\title{
Oo-site: A dashboard to visualize gene expression during Drosophila oogenesis reveals meiotic entry is regulated post-transcriptionally
}

\author{
Elliot T. Martin ${ }^{1 *}$, Kahini Sarkar ${ }^{1,4}$, Alicia McCarthy ${ }^{1}$, and Prashanth Rangan ${ }^{1,4^{*}}$ \\ 'Department of Biological Sciences/RNA Institute, University at Albany SUNY, Albany, NY \\ 12202 \\ ${ }^{4}$ Black Family Stem Cell Institute, Department of Cell, Developmental, and Regenerative \\ Biology, Icahn School of Medicine at Mount Sinai, 1 Gustave L. Levy Place, New York, NY \\ 10029, USA \\ ${ }^{*}$ Co-corresponding authors
}

Email: etmartin@albany.edu and prashanth.rangan@mssm.edu

\section{Summary}

Determining how stem cell differentiation is controlled has important implications for understanding the etiology of degenerative disease and designing regenerative therapies. In vivo analyses of stem cell model systems have revealed regulatory paradigms for stem cell selfrenewal and differentiation. The germarium of the female Drosophila gonad, which houses both germline and somatic stem cells, is one such model system. Bulk mRNA sequencing (RNA-seq), single-cell (sc) RNA-seq, and bulk translation efficiency of mRNAs are available for stem cells and their differentiating progeny within the Drosophila germarium. However, visualizing those data is hampered by the lack of a tool to spatially map gene expression and translational data in the germarium. Here, we have developed Oo-site (https://www.ranganlab.com/Oo-site), a tool for visualizing bulk RNA-seq, scRNA-seq, and translational efficiency data during different stages of germline differentiation, that makes these data accessible to non-bioinformaticians. Using this tool, we recapitulated previously reported expression patterns of developmentally regulated genes and discovered that meiotic genes, such as those that regulate the synaptonemal complex, are regulated at the level of translation.

\section{Introduction}

The Drosophila ovary provides a powerful system to study stem cell differentiation in vivo (Bastock and St Johnston, 2008; Eliazer and Buszczak, 2011; Lehmann, 2012; Spradling et al., 2011). The Drosophila ovary consists of two main cell lineages, the germline, which ultimately gives rise to 
eggs, and the soma, which surrounds the germline and plays a supportive role in egg development (Eliazer and Buszczak, 2011; Roth, 2001; Schüpbach, 1987; Xie and Spradling, 2000). Each stage of Drosophila female germline stem cell (GSC) differentiation is observable and identifiable, allowing GSC development to be easily studied (Bastock and St Johnston, 2008; Lehmann, 2012; Xie and Spradling, 1998). Specifically, female Drosophila GSCs undergo an asymmetric division, giving rise to another GSC and a cystoblast (CB) (Figure 1A) (Chen and McKearin, 2003b; McKearin and Ohlstein, 1995; Xie and Spradling, 1998). The GSC and CB are marked by a round structure called the spectrosome (Figure 1A) (De Cuevas and Spradling, 1998; Zaccai and Lipshitz, 1996). The CB then undergoes four incomplete divisions resulting in 2-, 4-, 8-, and finally 16-cell cysts (CC), which are marked by an extended structure called the fusome (Figure 1A) (Chen and McKearin, 2003a, 2003b; De Cuevas and Spradling, 1998). In the $16-\mathrm{CC}$, one of the cyst cells is specified as the oocyte, while the other 15 cells become nurse cells, which provide proteins and mRNAs to support the development of the oocyte (Figure 1A) (Bastock and St Johnston, 2008; Carpenter, 1975; Huynh and St Johnston, 2000, 2004; Navarro et al., 2001; Theurkauf et al., 1993). The 16-CC is encapsulated by somatic cells and buds off from the germarium, forming an egg chamber (Figure 1A) (Bastock and St Johnston, 2008; Forbes et al., 1996; Xie and Spradling, 2000). In each chamber, the oocyte grows as the nurse cells synthesize and then deposit mRNAs and proteins into the oocyte, which eventually gives rise to a mature egg (Bastock and St Johnston, 2008; Huynh and St Johnston, 2000).

Expression of differentiation factors, including those that regulate translation, results in progressive differentiation of GSCs to an oocyte (Blatt et al., 2020; Slaidina and Lehmann, 2014). In the CB, Bag-of-marbles (Bam) expression promotes differentiation and the transition from CB to 8-CC stage (Chen and McKearin, 2003a; McKearin and Ohlstein, 1995; Ohlstein and McKearin, 1997). In the 8-CC, RNA-binding Fox protein 1 (Rbfox1) promotes exit from the mitotic cell cycle into meiosis (Carreira-Rosario et al., 2016). Both the differentiation factors Bam and Rbfox1 affect the translation of mRNAs to promote differentiation (Carreira-Rosario et al., 2016; Li et al., 2009; Tastan et al., 2010). In addition, in 8-CCs, recombination is initiated across many cyst cells and then eventually is restricted to the specified oocyte (Hinnant et al., 2020; Huynh and St Johnston, 2000). Neither the mRNAs that are translationally regulated during this progressive differentiation nor how recombination is temporally regulated is fully understood (Cahoon and Hawley, 2016; Carreira-Rosario et al., 2016; Flora et al., 2018; Rubin et al., 2020; Slaidina and Lehmann, 2014; Tanneti et al., 2011; Wei et al., 2014). 
Within the germarium, the germline is surrounded by and relies on distinct populations of somatic cells for signaling, structure, and organization (Roth, 2001; Schüpbach, 1987; Xie and Spradling, $2000,1998)$. For example, the terminal filament, cap, and anterior-escort cells act as a somatic niche for the GSCs (Decotto and Spradling, 2005; Lin and Spradling, 1993; Wang and PageMcCaw, 2018; Xie and Spradling, 2000). Once GSCs divide to give rise to CBs, posterior escort cells guide $\mathrm{CB}$ differentiation by encapsulating the $\mathrm{CB}$ and the early-cyst stages (Kirilly et al., 2011; Shi et al., 2021; Upadhyay et al., 2016). Follicle stem cells (FSCs), which are present towards the posterior of the germarium, divide and differentiate to give rise to follicle cells, (FCs) which surround the late-stage cysts that give rise to egg chambers (Margolis and Spradling, 1995; Nystul and Spradling, 2010; Rust et al., 2020). FSCs also give rise to stalk cells and polar cells which connect the individual egg chambers that comprise the ovariole (Margolis and Spradling, 1995; Nystul and Spradling, 2010; Rust et al., 2020; Sahai-Hernandez et al., 2012).

While there is a wealth of bulk RNA-seq, single-cell mRNA-seq (scRNA-seq), and translational efficiency data from polysome-seq experiments for the cells in the germarium, there are several hurdles for easy utilization of this data:

1. scRNA-seq has exquisite temporal resolution but it can miss some lowly expressed transcripts which are better captured by bulk RNA-seq (Lähnemann et al., 2020). However, there is no easy way to compare these two data sets.

2. While scRNA-seq provides mRNA levels, it does not indicate if these mRNAs are translated, especially in the germline where translation control plays an important role (Blatt et al., 2020; Slaidina and Lehmann, 2014).

3. Lastly, there is a barrier to the visualization of the data for those who are not experienced in bioinformatics.

Here, we have developed a tool that we call Oo-site which integrates bulk RNA-seq, scRNA-seq, and polysome-seq data to spatially visualize gene expression and translational efficiency in the germarium.

\section{Results}

To make bulk RNA-, scRNA-, and polysome-, seq data accessible to the community, we have collated and reprocessed previously published sequencing datasets of ovaries enriched for GSCs, CBs, cysts, and egg chambers (Figure 1B). Notably, each genetically enriched sample 
100

101

102

103

104

105

106

107

108

109

110

111

112

113

114

115

116

117

118

119

120

121

122

123

124

125

126

127

128

129

130

131

132

133

had matched bulk RNA-seq and polysome-seq libraries prepared, allowing for simultaneous readout of mRNA level and translation status (Supplemental Figure 1A). One limitation is that the enriched cyst stages do not resolve each distinct stage of cyst development, instead, these samples represent a mixture of cyst stages. Therefore to supplement the enrichment data, we have integrated scRNA-seq data from Slaidina et al. which provides a more discrete temporal resolution of the cyst stages (Slaidina et al., 2021). We present these data as a tool called Oosite (https://www.ranganlab.com/Oo-site), a collection of interactive visualizations that allows researchers to easily input a gene or collection of genes of interest to determine their expression pattern(s).

Oo-site consists of three modules: ovary-map, ovary-heatmap, and ovary-violin (Figure 1C). Each module allows users to visualize expression from matched mRNA-seq and polysome-seq data of genetically enriched stages of early GSC differentiation as well as previously published scRNAseq data (Slaidina et al., 2021). Additionally, we have integrated scRNA-seq expression data for genes that cluster in somatic cell populations that reside in the germarium (Slaidina et al., 2021), however, here we focus on the germline (Slaidina et al., 2021). Ovary-map allows users to visualize the expression of a single gene over the course of differentiation in the framework of a germarium schematic, which contextualizes staging for those less familiar with Drosophila oogenesis. Ovary-heatmap consists of a clustered, interactive heatmap of genes determined to be differentially expressed that allows users to explore expression trends over-development (Figure 1B, Supplemental Figure 1B-C'). Finally, ovary-violin allows users to visualize the expression of multiple genes over the course of differentiation (Figure 1C). These groups of genes can be selected either by a GO-term of interest or a custom list of genes supplied by the user. The user can download a spreadsheet of gene expressions corresponding to the subset of selected or input genes. Finally, Oo-site incorporates a reporting tool that generates a downloadable report of the visualization(s) in a standardized format to facilitate their use for publication (Figure 1C). Researchers can use these datasets to enhance hypothesis generation or to confirm expression patterns observed from other methods.

Using Oo-site, we first determined if the bulk RNA-seq data that was acquired by enriching for specific stages of germline development is representative of the gene expression patterns from purified cell types. We compared bulk RNA-seq data obtained by enriching for GSC and CB cell types without purification from somatic cells (Figure 1C) to the GSC and CB data from Wilcockson et al. where they included a fluorescent-assisted cell sorting (FACS) step to eliminate somatic 
cells so that a pure population of these germline cells was sequenced (Wilcockson and Ashe, 2019). We analyzed the expression of genes that Wilcockson et al. identified as 2-fold or more down- or upregulated with a p-value $<0.01$. We found that in the enriched bulk RNA-seq data these genes followed similar trends as identified by Wilcockson et al., indicating that despite the lack of FACS purification, enrichment of cell types reproduces meaningful mRNA expression changes over these stages (Supplemental Figure 2A-A').

To determine if the bulk RNA-seq data recapitulates genuine changes in gene expression, we compared the expression of ribosomal small subunit protein $19 b$ (RpS19b) in bulk RNA-seq to scRNA-seq data. Our bulk RNA-seq data, as well as the available scRNA-seq data indicated that $R p S 19 b$ was highly expressed in GSCs, decreased during differentiation in the cyst stages and was greatly decreased in expression in early egg chambers, consistent with previous reports (Fig 2A-B) (McCarthy et al., 2021; Sarkar et al., 2021). To further validate this expression pattern, we probed the expression of RpS19b in vivo using in situ hybridization as well as an RpS19b::GFP line that is under endogenous control elements (McCarthy et al., 2021). We found that RpS19b was present in the GSCs and diminishes in the cyst stages both at the mRNA and protein level (Figure 2C-E'). Additionally, RpS19b::GFP expression resembled its mRNA expression indicating that its dynamic expression is achieved primarily through modulating the mRNA level of $R p S 19 b$, consistent with its moderate to high translational efficiency in early stages (Figure 2C-D, Supplemental Figure 2B). Thus, enriching for specific germline stages captures changes to gene expression in the germline. However, we note that care should be taken in interpreting bulk RNA-seq results as the data may be influenced by the somatic cells present in the samples. However, simultaneous comparison with scRNA-seq can alleviate this problem.

To determine the groups of genes that change as the GSCs differentiate into an egg, we used gene ontology (GO)-term analysis to probe for pathways that change at the level of RNA using bulk RNA-seq data. We did not identify any significant GO-terms in genes that are differentially expressed between GSCs and CBs. We found that genes with lower expression in GSCs compared to differentiating cysts are enriched in the GO-term polytene chromosome puffing which is consistent with GO-terms identified in Wilcockson et al. for genes that are expressed at lower levels in GSCs than in differentiating cysts than GSCs (Figure 3A). We also identified the polytene chromosome puffing GO-term in genes downregulated in CBs compared to cysts. Additionally, we observed that several GO-terms involving peptidase activity were enriched in genes upregulated in GSCs and CBs compared to cysts (Figure 3B). This is consistent with findings 
suggesting that peptidases can be actively regulated during differentiation and can influence stem cell fate (Han et al., 2015; Perišić Nanut et al., 2021; Tiaden et al., 2012). We found that two GOterms related to glutathione transferase activity were enriched in genes downregulated in GSCs and CBs compared to ovaries from young-wildtype (young-WT) flies and in CBs compared to differentiating cysts, suggesting that metabolic processes may be altered during GSC differentiation. Additionally, comparison of CBs and differentiating cysts to young-WT, which contain early egg chambers, indicated that downregulated genes were enriched in GO-terms involving vitelline and eggshell coat proteins (Figure 3A).

Next, to determine if our data could resolve large-scale expression changes that occur during oogenesis we examined the expression of genes in the GO-term meiotic cell cycle. Meiosis is initiated during the cyst stages of differentiation and therefore we would expect genes in the category, in general, to increase in expression in the >bam RNAi; hs-bam samples (Carpenter, 1979; Tanneti et al., 2011). We were surprised to find no significant change in the mean mRNA expression of genes in this GO-term in any of our enriched stages compared to enriched GSCs, though this does not preclude gene expression changes for individual genes (Supplemental Figure 3A). However, this is consistent with the observation that several factors that promote meiosis I are transcribed in the GSCs and the cells that follow (McCarthy et al., 2021). This suggests that, in general, a transition from a mitotic state to a meiotic state is not driven by large changes in mRNA levels of meiotic genes.

As we did not see overall changes to mRNA levels of genes in the GO-term meiotic cell cycle, we next examined the polysome-seq data of those genes to determine if changes in expression might occur at the level of translation. Polysome-seq uses polysome profiling to separate mRNAs that are associated with polysomes which form by mRNAs engagement with multiple ribosomes. To quantify the degree to which an mRNA is associated with polysome fractions, we compared the relative abundance of mRNAs from the polysome fractions to their relative expression using corresponding input lysates to calculate a metric referred to as translational efficiency (TE). Indeed, genes in the meiotic cell cycle GO-term had a significant increase in translation efficiency in CBs and a more dramatic increase in cysts despite no significant changes to the overall mRNA level of these genes (Supplemental Figure 3A-B). Based on scRNA-seq data, the expression of meiotic cell cycle genes increased slightly but significantly in the 4-CC cluster with a median increase in expression of 1.25 fold (Supplemental Figure 3C). This suggests that some genes in the meiotic cell cycle GO-term may be regulated at the mRNA level, but as a group this 
regulation is modest. This is likely because genes in this GO-term are robustly expressed even in GSCs as the median mRNA level of meiotic cell cycle genes in enriched GSCs is 36.1 TPM, which exceeds the $70^{\text {th }}$ expression percentile among all genes in enriched GSCs.

To validate this finding, we examined orientation disrupter (ord) because it is a well-characterized gene, is required for sister chromatid cohesion, and has previously been reported to peak in expression as meiosis begins in Drosophila (Bickel et al., 1997, 1996; Khetani and Bickel, 2007). Our Oo-site results suggested that ord mRNA was expressed before meiosis, both from bulk RNA-seq (Figure 4A) and scRNA-seq (Supplemental Figure 3D) consistent with reports that chromosome pairing initiates before meiotic entry (Christophorou et al., 2013; Joyce et al., 2013). However, polysome-seq data were consistent with the observation that Ord protein expression increases during the cyst stages due to translation (Figure 4B). This led us to predict that ord mRNA would be expressed before meiosis, and that Ord protein expression would increase during the cyst stages as previously observed, implying a change in the translation status of ord mRNA. To test this, we performed fluorescent in situ hybridization against GFP in a fly expressing Ord-GFP under the control of the ord promoter and 5'UTR. We visualized both the GFP protein and the mRNA and observed increased expression of Ord::GFP protein but consistent ord::GFP mRNA expression, indicating that Ord is controlled post-transcriptionally, likely at the level of translation based on our polysome-seq data (Figure 4C-D'). This finding also underscores the utility of Oo-site in exploring post-transcriptional gene expression changes.

To further determine if meiosis is regulated post-transcriptionally, we examined the expression of genes in the GO-term "Double-strand break repair", which is known to occur during meiosis 1 (Hughes et al., 2018; Page and Hawley, 2003). Double-stranded breaks are resolved before egg chamber formation (Hughes et al., 2018; Mehrotra and McKim, 2006; Page and Hawley, 2003). At the level of input mRNA, we found no significant changes in the expression of genes in this category compared to enriched GSCs (Figure 5A). From scRNA-seq data, the median expression of double-strand break repair genes significantly increases, but the median increase was only 1.05 fold in 4-CCs and 1.06 in 8-CCs compared to the GSC/CB/2CC group (Figure 5B). This suggests that double-strand break repair gene transcription begins in GSC stages and increases modestly during the cyst stages.

234 In contrast, we found a significant increase in the median translational efficiency of double-strand 235 break repair genes, with a 1.20 fold increase in the median translational efficiency in enriched 
CBs and a 1.56 fold increase in enriched cysts compared to enriched GSCs (Figure 5C). In young-WT the median fold change in translational efficiency decreased slightly but significantly compared to enriched GSCs at 0.95 fold. This is consistent with the observed progression of double-stranded break repair that occurs in vivo. This demonstrates that Oo-site can be used to derive insights into biological processes that may be changing during early oogenesis (Mehrotra and McKim, 2006; Page and Hawley, 2003). That key processes related to meiosis and differentiation are controlled post-transcriptionally is consistent with the importance of proteins that regulate translation such as Bam and Rbfox 1 in differentiation and meiotic commitment during Drosophila oogenesis (Blatt et al., 2020; Carreira-Rosario et al., 2016; Flora et al., 2018; Kim-Ha et al., 1995; Li et al., 2009; Slaidina and Lehmann, 2014; Tastan et al., 2010).

\section{Discussion}

We have developed an application that facilitates analysis of bulk RNA-seq, sc RNA-seq, and polysome-seq data of early Drosophila oogenesis that is accessible to non-bioinformaticians. We have demonstrated its utility in representing expression at the mRNA and translation level. Additionally, we have demonstrated that it can be used to visualize the expression of groups of genes over development to facilitate hypothesis development. As with all sequencing data, care should be taken to validate findings from Oo-site as sequencing can be influenced by a myriad of factors.

We have used Oo-site to discover that key meiosis regulators such as proteins of the synaptonemal complex and proteins of the double-strand break machinery are regulated at the level of translation. This adds to our understanding of the mechanisms regulating the mitotic to meiotic transition. In future work, identifying the factors mediating the widespread posttranscriptional regulation of crucial meiotic genes and mechanistically how it drives the mitotic to meiotic transition is of high importance.

High-throughput sequencing has enabled researchers to generate more data than ever before However, the development of analysis tools that are usable without bioinformatics training that enable users to make sense of these data to generate hypotheses and novel discoveries has lagged (Shachak et al., 2007). Oo-site allows for hypothesis generation and discovery using the powerful model system of Drosophila oogenesis. We believe Oo-site might also have utility as a teaching and demonstration tool to introduce students to the power of genomics in developmental biology. The open-source nature of this software facilitates future tool development, which will be 
crucial as more researchers delve into more data-intensive scRNA-seq, where visualization tools

271 are limited and produce plots that may be difficult to interpret for those not versed in

272 bioinformatics. Oo-site can be supplemented in the future to include additional data such as Cut

273 and Run for various chromatin marks, nascent mRNA transcription using transient transcriptome

274 sequencing or similar techniques, or protein levels from mass-spectroscopy to further extend its

275 utility in hypothesis development.

276

\section{Acknowledgements}

278 We thank the Drs. Ruth Lehmann and Maija Sladina for sharing scRNA-seq data with us before

279 publication of the manuscript. We are grateful to all members of the Rangan laboratory for 280 discussion and comments on the manuscript. We thank Noor Kotb for naming the dashboard Oo281 site. We also thank Dr. Florence L. Marlow for critically reading and editing the manuscript. P.R. 282 is funded by the National Institutes of Health NIGMS (RO1GM11177 and RO1GM135628).

\section{Materials and Methods}

285 The following RNAi stocks were used in this study; ord-GFP(Bickel Lab), Rps19b::GFP (McCarthy et al., 2021), UAS-Dcr2;nosGAL4 (Bloomington stock \#25751), bam RNAi (Bloomington \#58178), hs-bam/TM3 (Bloomington \#24637),

\section{Sequencing data}

290 Polysome-seq data were obtained from previous studies conducted by the Rangan lab. Data are 291 available via the following GEO accession numbers:

292 >UAS-tkv GSE171349

293 >bam RNAi GSE171349, GSE166275

294 >bam RNAi; hs-bam GSE143728

295 Young-WT GSE119458

296

297 Single-cell sequencing data were obtained from Slaidina et al., GEO accession: GSE162192

298

\section{Code Availability}

300 All code used in the preparation of this manuscript is available on Github at 301 https://github.com/elliotmartin92/Developmental-Landscape/tree/master/Paper 
303 The codebase underlying Oo-site is available on GitHub at

304 https://github.com/elliotmartin92/Developmental-Landscape/tree/master/ShinyExpresionMap

305

306

Antibodies

307 Mouse anti-1B1 1:20 (DSHB 1B1), rabbit anti-GFP 1:2000 (abcam, ab6556), rabbit anti-Vasa

308 1:4000 (Upadhyay et al., 2016), chicken anti-Vasa 1:4000 (Upadhyay et al., 2016)

309

310

\section{Polysome-seq}

311 Flies ready for heat shock were placed at $37^{\circ} \mathrm{C}$ for 2 hours, moved to room temperature for 4

312 hours, and placed back into $37^{\circ} \mathrm{C}$ for 2 additional hours. Flies were then left overnight at room

313 temperature and the same heat shocking procedure was repeated for a total of 2 days. Flies were

314 then dissected in 1x PBS. Polysome-seq was performed as previously described (McCarthy et

315 al., 2021).

316

Polysome-seq data processing

318 Reads were mapped to the Drosophila genome (dm6.01) using STAR version 2.6.1c. Mapped 319 reads were assigned to features also using STAR. Translation efficiency was calculated as in 320 (Flora et al., 2018) using an R script which is available in the Oo-site Github repo. Briefly, TPMs 321 (transcripts per million) values were calculated The $\log _{2}$ ratio of TPMs between the polysome 322 fraction and total mRNA was calculated as such to prevent zero counts from overly influencing

323 the data and to prevent divide by zero errors: $\frac{\text { olysome }_{T P M}+1}{\text { Input }_{T P M}+1}$. This ratio represents TE, TE of each 324 replicate was averaged and standard error about the calculated average for each gene was 325 calculated.

\section{Differential Expression}

328 Differential expression analysis between all bulk RNA-seq samples in a pairwise manner was 329 performed using DEseq2 (Love et al., 2014). Differential expression was considered as 330 Foldchange $>|4|$ fold, FDR $<0.05$.

331 Differential expression analysis between all polysome-seq samples in a pairwise manner was performed using DEseq2 (Love et al., 2014) using the model type + genotype + genotype:type with LRT (reduced $=\sim$ type + genotype) to test for changes in polysome counts controlling for

334 input counts. Differential expression was considered as (Foldchange $>|2|$ fold, pvalue $<0.05$ ) 
Differentially expressed genes between all germline clusters from scRNA-seq was determined using the FindAllMarkers function from Seurat (Hao et al., 2021). Cutoff was logfc.threshold = 0.75 .

Differentially expressed genes between all germarium soma clusters from scRNA-seq was determined using the FindAllMarkers function from Seurat (Hao et al., 2021). Cutoff was logfc. threshold $=0.75$.

\section{GO term heatmaps}

GO-term enrichment analysis was performed using Panther (release 20210224) using the default settings for an Overrepresentation Test of genes differentially expressed between Input samples. Top 5 GO-terms based on fold enrichment of each category were plotted using ggplot2 (Wickham, 2016).

\section{Fluorescent in situ hybridization}

A modified in situ hybridization procedure for Drosophila ovaries was followed from Sarkar et al. (2021). Probes were designed and generated by LGC Biosearch Technologies using Stellaris ${ }^{\circledR}$ RNA FISH Probe Designer, with specificity to target base pairs of target mRNAs. Ovaries (3 pairs per sample) were dissected in RNase free 1X PBS and fixed in $1 \mathrm{~mL}$ of $5 \%$ formaldehyde for 10 minutes. The samples were then permeabilized in $1 \mathrm{~mL}$ of Permeabilization Solution (PBST+1\% Triton X-100) rotating in RT for 1 hour. Samples were then washed in wash buffer for 5 minutes (10\% deionized formamide and 10\% 20x SSC in RNase-free water). Ovaries were covered and incubated overnight with $1 \mathrm{ul}$ of the probe in hybridization solution $(10 \%$ dextran sulfate, $1 \mathrm{mg} / \mathrm{ml}$ yeast tRNA, 2 mM RNaseOUT, 0.02 mg/ml BSA, 5x SSC, 10\% deionized formamide, and RNasefree water) and primary antibody at $30^{\circ} \mathrm{C}$. Samples were then washed 2 times in $1 \mathrm{~mL}$ wash buffer with 1 ul of corresponding secondary antibody for 30 minutes each and mounted in Vectashield (VectaLabs).

\section{Quantification of Stainings}

Stainings were quantified using the Fiji Measure tool. Images were aligned and cropped to place the stem cell niche at $x=0$. Individual cells were outlined within the germarium and Measure was 
364 used to calculate the Mean intensity of staining within the cell as well as the $X$ coordinate of the

365 centroid of the cell. Values were normalized to 1 by dividing Mean Intensity values by the

366 maximum of the Mean Intensity per germarium. Data were plotted using ggplot2 and a fit line was

367 added using ggplot2 geom_smooth with a "loess" function with default settings. The shaded area

368 around the line represents standard error.

369 
A

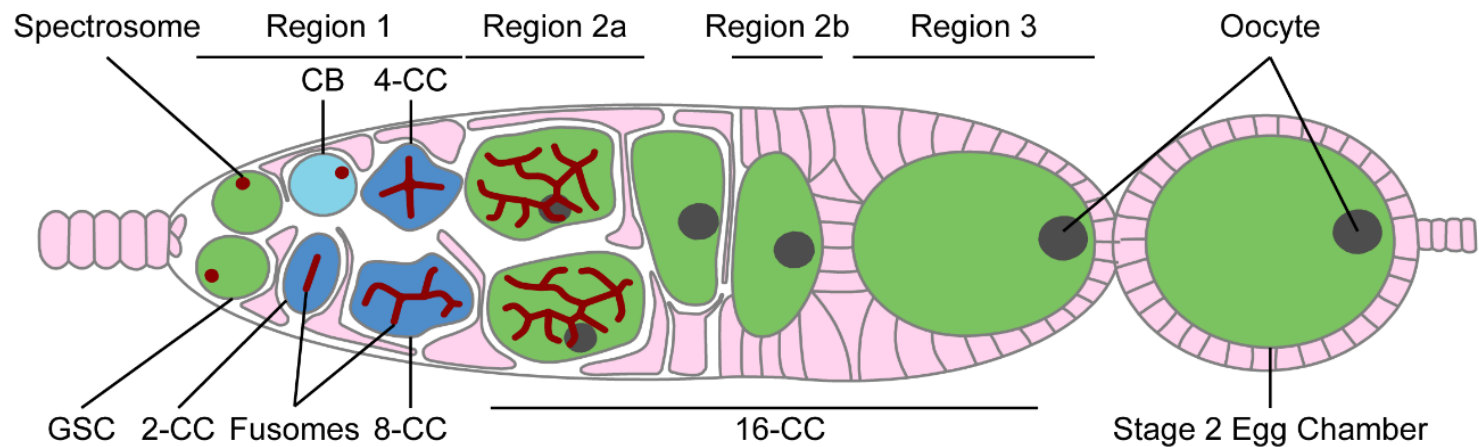

B

\begin{tabular}{|c|c|}
\hline Genotype & Enriched cell type \\
\hline >UAS-tkv & GSCs \\
\hline > bam RNAi & CBs \\
\hline >bam RNAi; hs-bam & Cysts \\
\hline
\end{tabular}

Young - WT

Germarium and early egg chambers

C

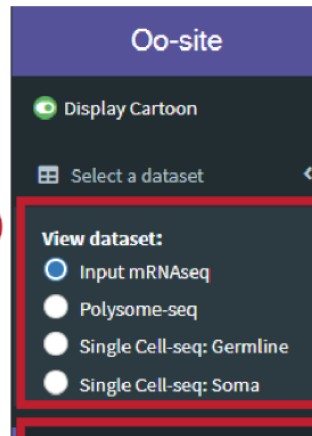

(3)

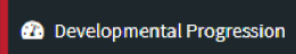

iil Heatmap

(1)

때 Gene Groups

Lt Generate report

(3) Take a tour!

$\equiv$

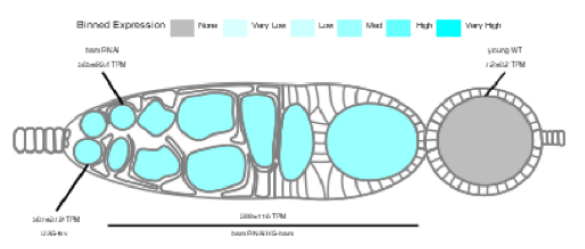

Controls

(4)

Data set

Symbol

Gene of Interest

RpS19b

$\square$ Display Expression values

$\square$ Display Stage Labels

372 Figure 1: Oo-site integrates and provides an interface for interacting with multi-omic data 373 covering major stages of Drosophila GSC differentiation. 
374 (A) Schematic illustrating developmental stages of germline development. (B) Summary of the 375 samples used for bulk RNA-seq and polysome-seq and the cell types these samples are enriched

376 for. (C) Screenshot of Oo-site dashboard, indicating: (1) "Take a Tour!" function, which guides the

377 user through the functionality and operation of Oo-site. (2) The available seq datasets which the

378 user can view, including RNA-seq of ovaries genetically enriched for developmental stages (bulk

379 RNA-seq), polysome-seq of ovaries genetically enriched for developmental stages (Polysome-

$380 \mathrm{seq}$ ), single-cell seq of germline stages (Single-Cell seq: Germline), and single-cell seq of somatic

381 stages in the germarium (Single-Cell seq: Soma). (3) the available visualizations which the user

382 can use, including viewing the expression of genes over development at the level of a single gene

383 (Developmental Progression), viewing all significantly changing genes as heatmaps (Heatmap),

384 and viewing groups of genes either derived from GO-term categories or supplied by the user

385 (Gene Groups). (4) The control panel, which the user can use to control the current visualization,

386 and (5) the Generate Report Function, which can be used to download a PDF report of either the 387 current visualization or all active visualizations. 
bioRxiv preprint doi: https://doi.org/10.1101/2022.01.31.478569; this version posted January 31, 2022. The copyright holder for this preprint (which was not certified by peer review) is the author/funder, who has granted bioRxiv a license to display the preprint in perpetuity. It is made available under aCC-BY-NC-ND 4.0 International license.

A

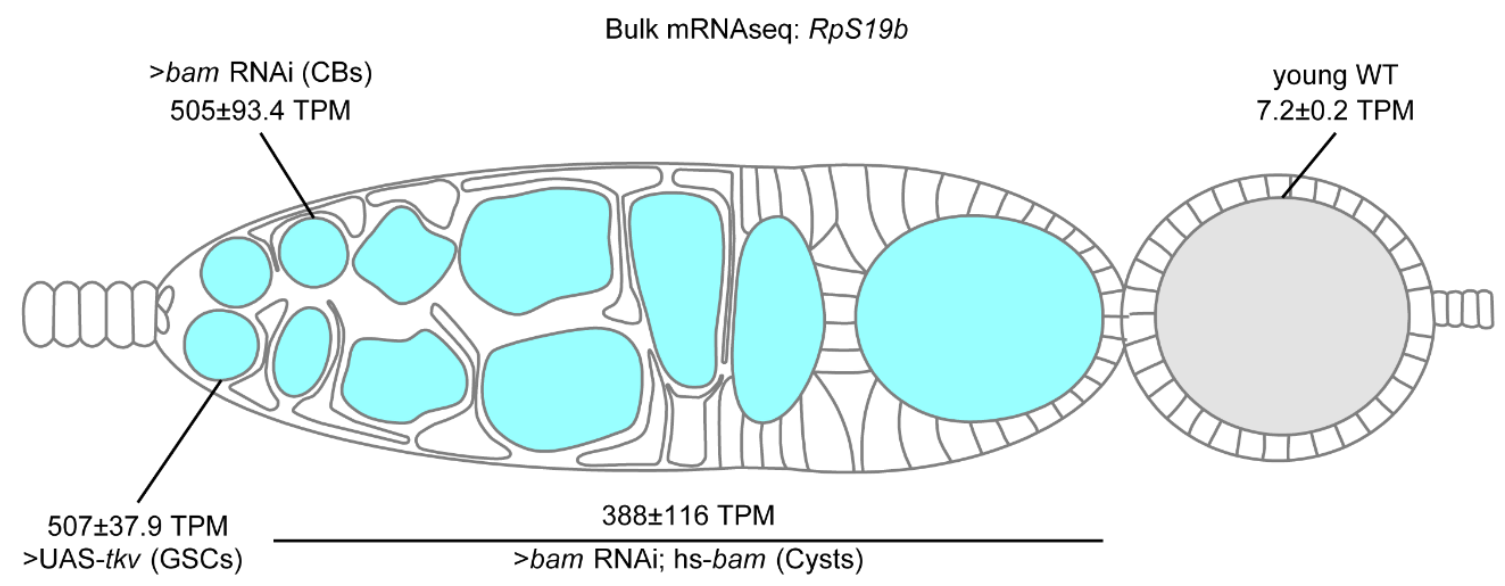

B

Germline scRNA-seq: $R p S 19 b$
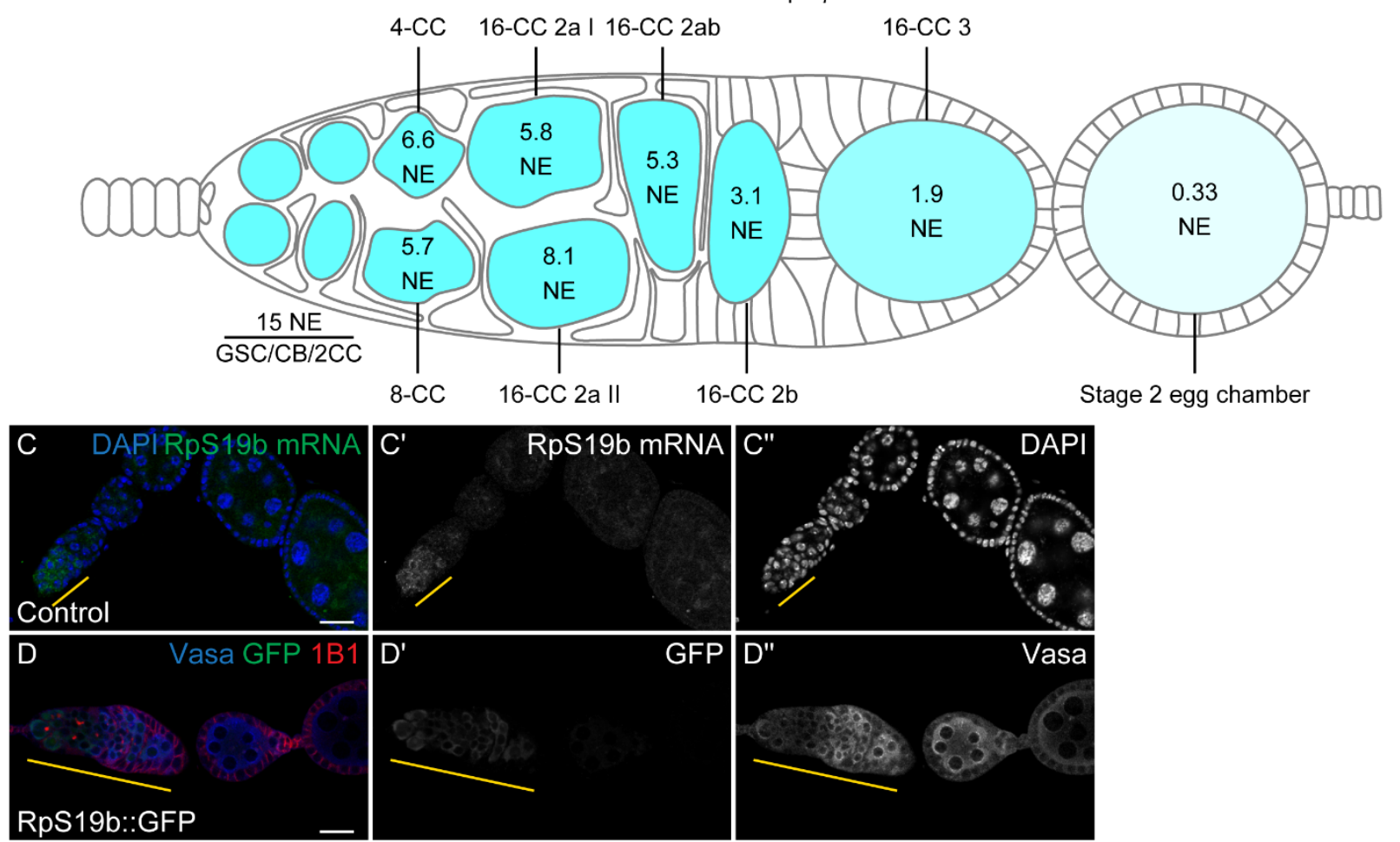

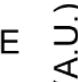
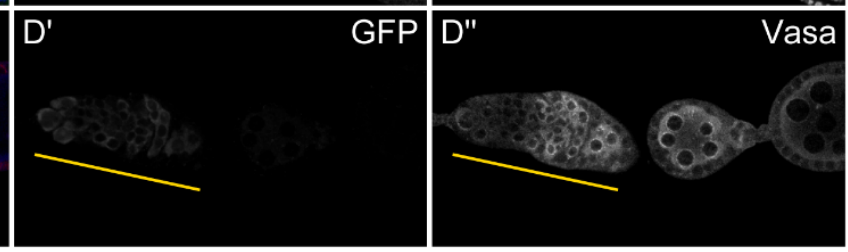

$\mathrm{E}^{\prime}$

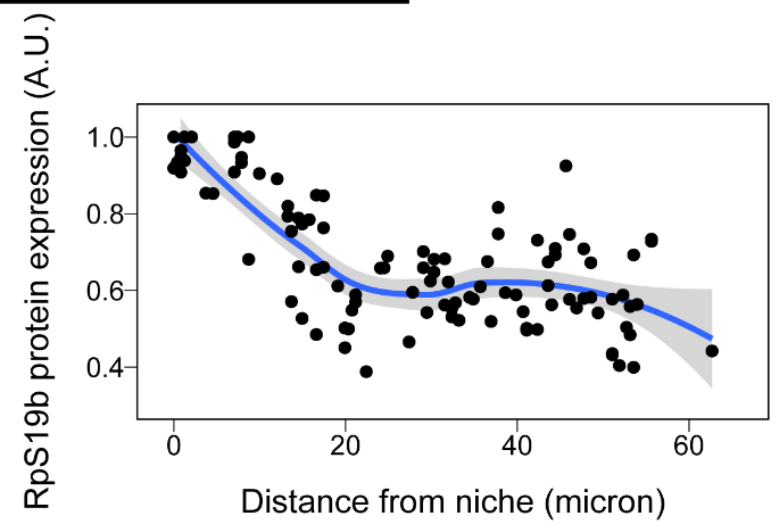


Figure 2: Oo-site allows for visualization of dynamically regulated genes

391 (A-B) Visualization of expression of RpS19b over germline development from (A) developmentally

392 enriched stages and (B) single-cell seq data indicate that the mRNA level of RpS19b decreases

393 starting in the cysts and is dramatically decreased in early egg chambers. Color indicates relative

394 expression and values indicate the $(A)$ mean TPM \pm standard error or $(B)$ the normalized

395 expression of RpS19b in each given stage. (C-C') Confocal images of ovaries with in situ

396 hybridization of RpS19b (green, middle greyscale) and stained for DAPI (blue, right greyscale)

397 demonstrate that the mRNA level of RpS19b decreases starting in the cyst stages and are

398 dramatically lower in early egg chambers consistent with the seq data. (D-D") Confocal images

399 of ovaries expressing RpS19b::GFP, visualizing (D') GFP (green, middle greyscale), (D") Vasa

400 staining (blue, right greyscale), and 1B1 (red) demonstrate that the protein expression of

401 RpS19b::GFP is consistent with its mRNA levels. (E-E') Quantifications of normalized mean

402 intensity of staining, $\mathrm{X}$-axis represents the distance in microns from the niche, $\mathrm{Y}$-axis represents

403 mean intensity normalized to the maximum mean intensity per germarium of (E) RpS19b mRNA

404 or (E') RpS19b::GFP. The line represents fit using a loess regression, shaded area represents

405 the standard error of the fit. ( $n=5$ germaria). 
bioRxiv preprint doi: https://doi.org/10.1101/2022.01.31.478569; this version posted January 31, 2022. The copyright holder for this preprint (which was not certified by peer review) is the author/funder, who has granted bioRxiv a license to display the preprint in perpetuity. It is made available under aCC-BY-NC-ND 4.0 International license.

A

Bulk mRNAseq: GO terms of downregulated genes

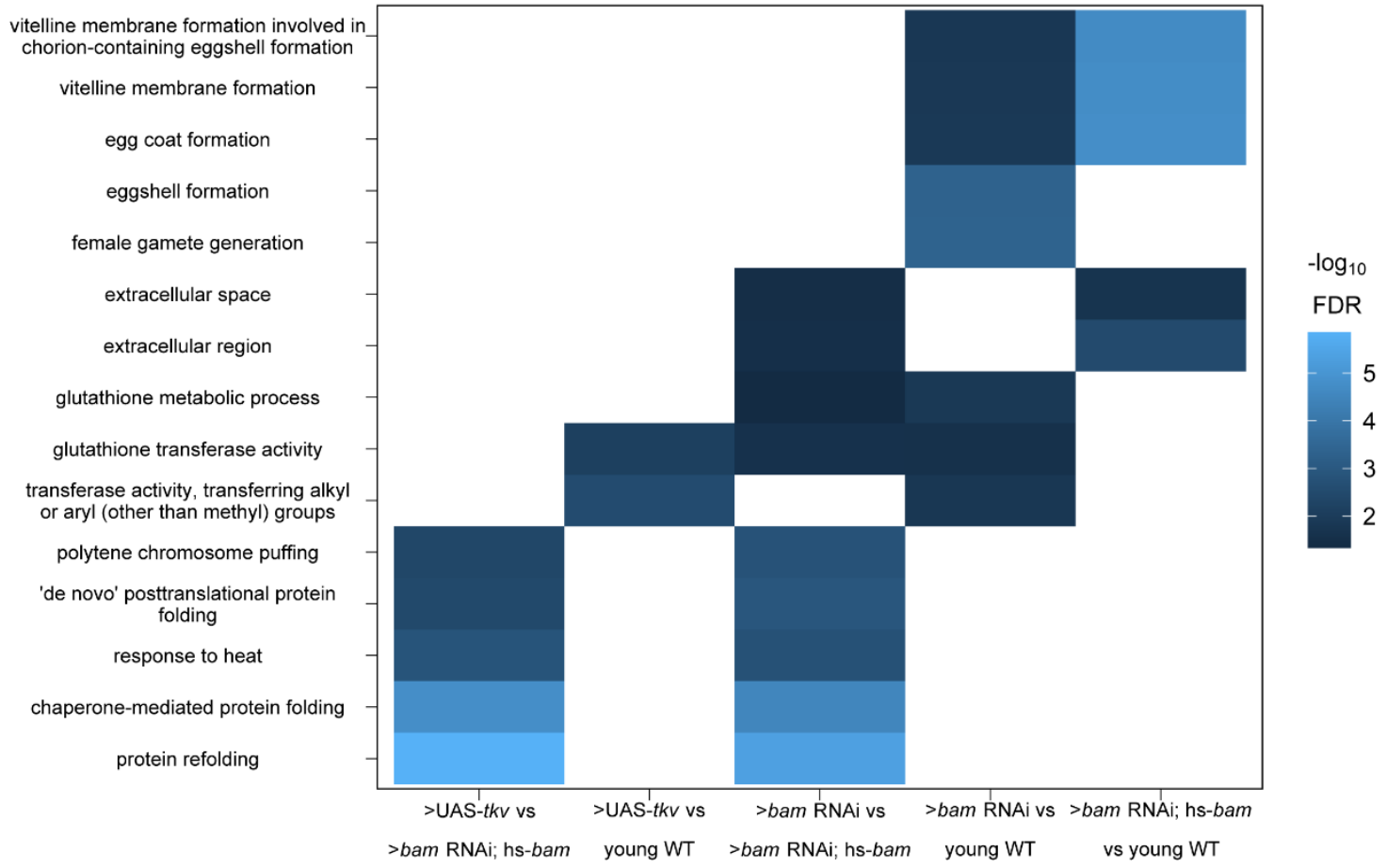

B

Bulk mRNAseq: GO terms of upregulated genes

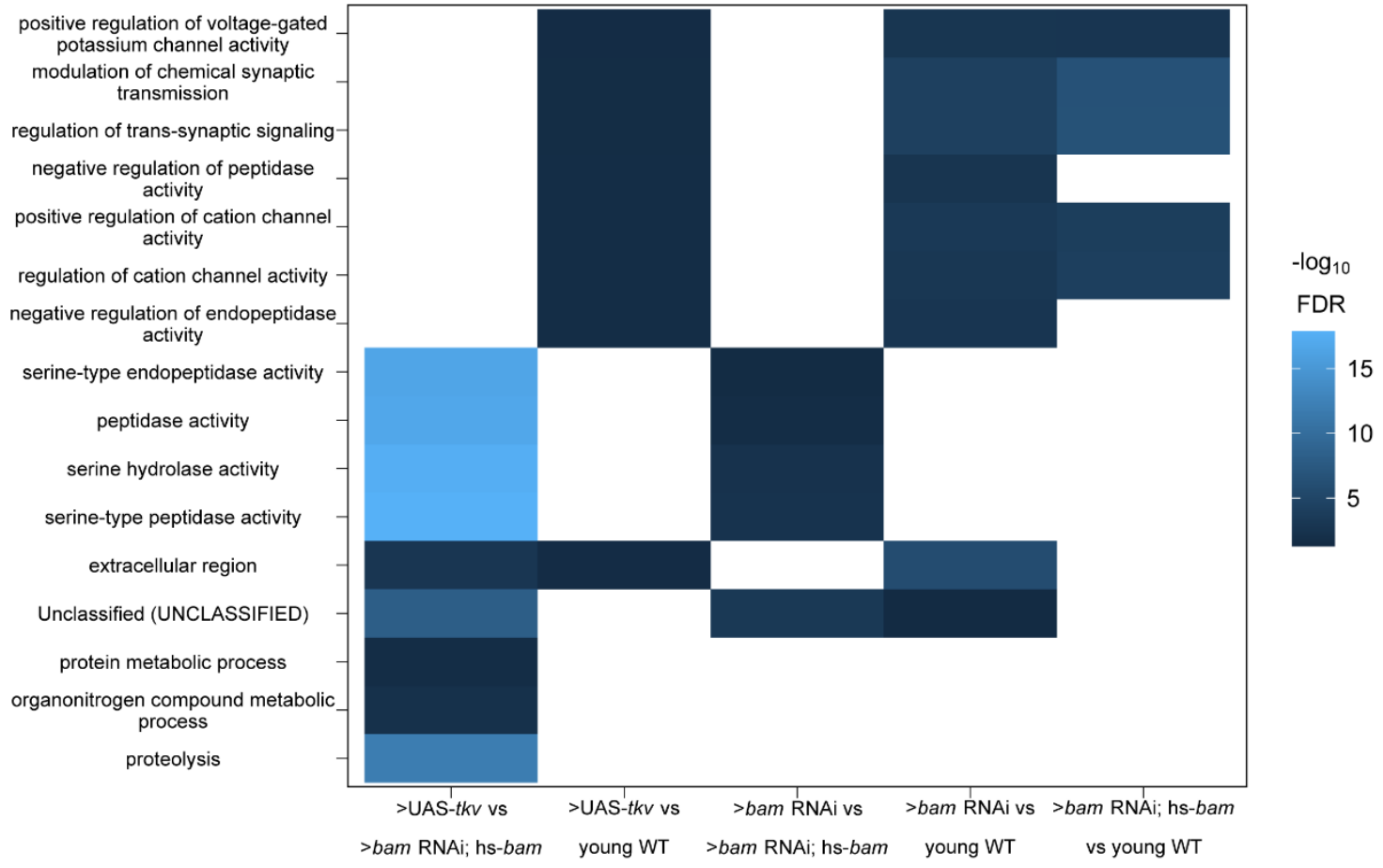


407 Figure 3: GO-terms enriched from differentially expressed genes between genetically 408 enriched developmental milestones

409 (A-B) Heatmaps of top five significant GO-terms by fold enrichment resulting from each pairwise

410 comparison of significantly $(A)$ downregulated or $(B)$ upregulated genes in the first genotype listed

411 relative to the second genotype listed in the $x$-axis from bulk RNA-seq of each developmentally

412 enriched stage. Comparisons that did not generate any significant GO-terms are omitted. 
A

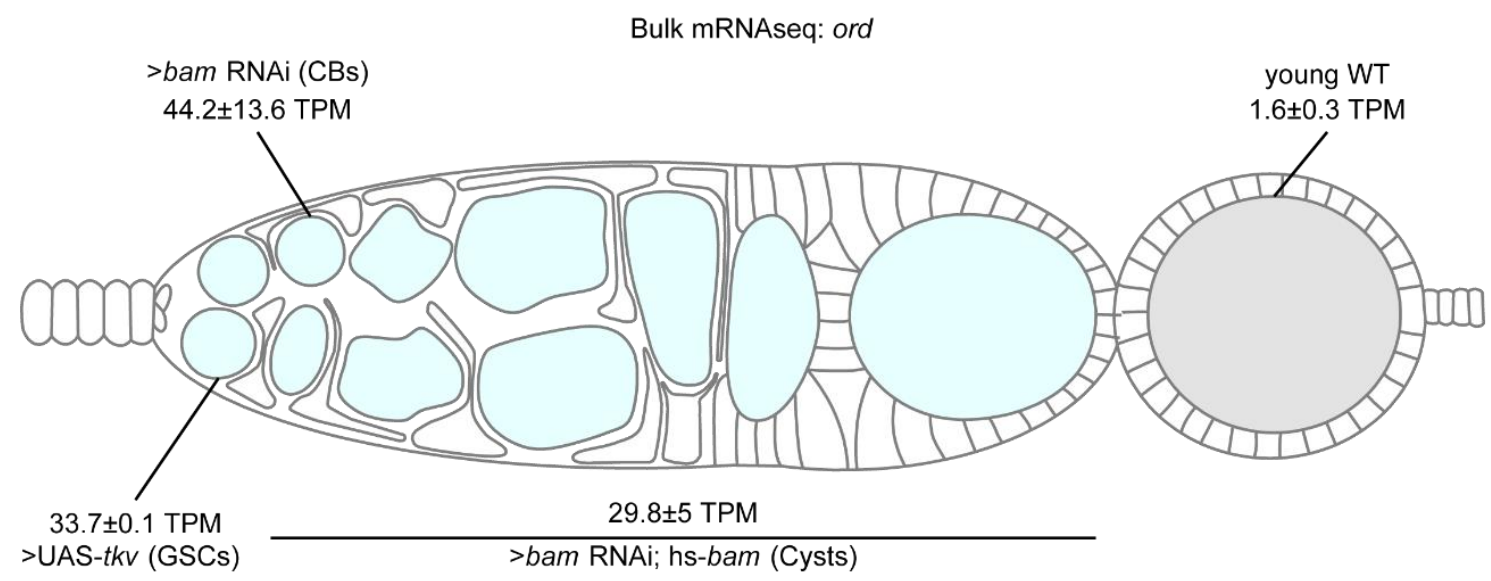

B
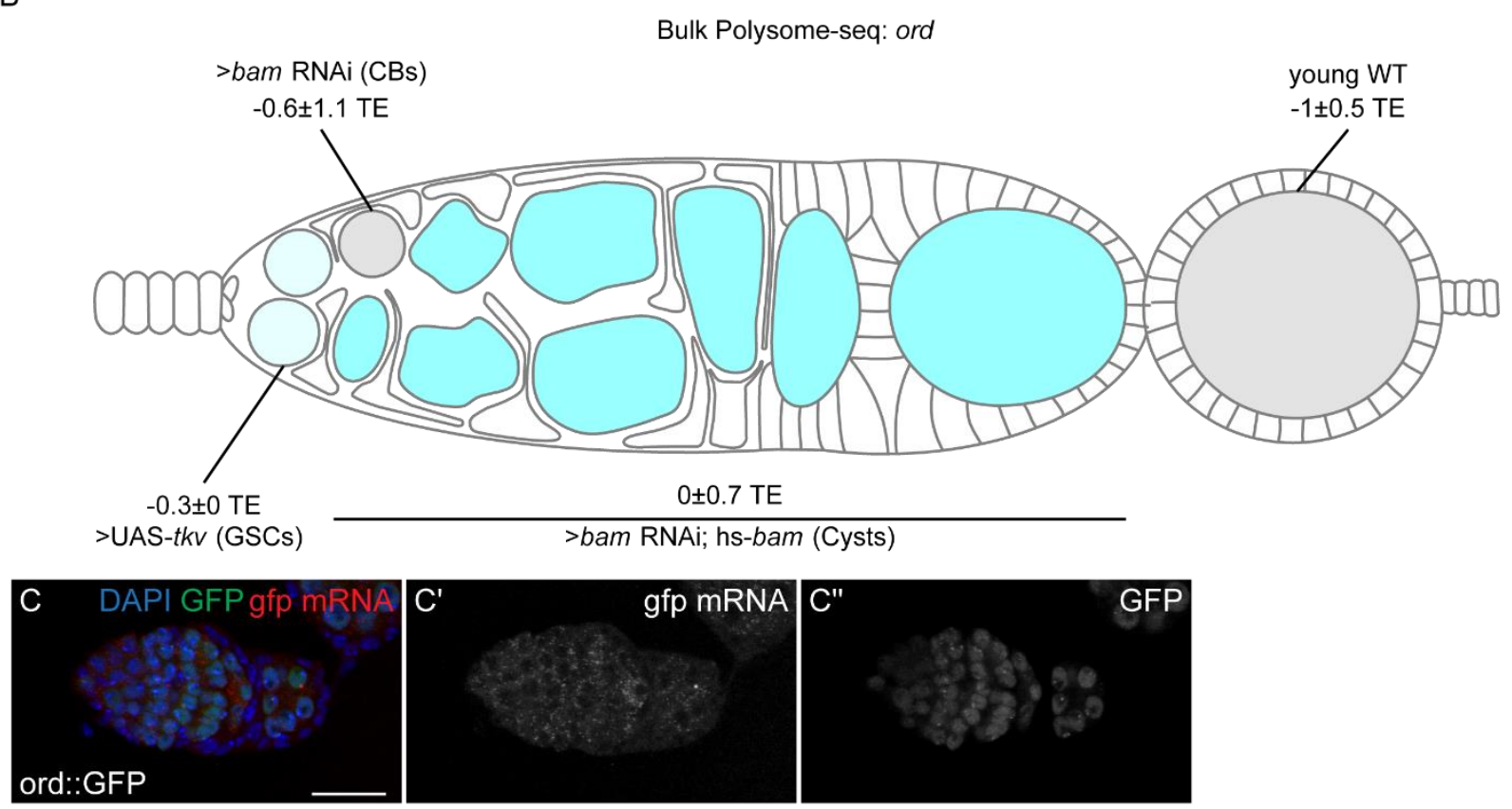

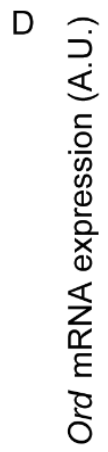

414

415

416

417

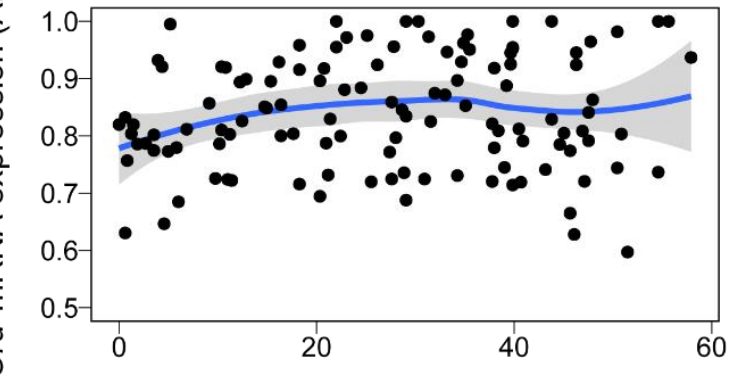

Distance from niche (micron)

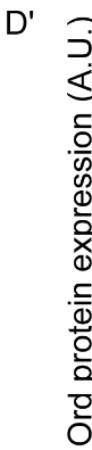

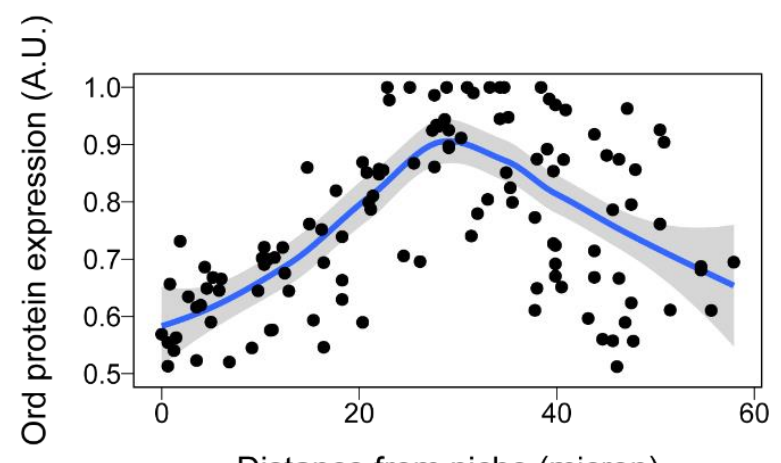

Distance from niche (micron)

Figure 4: Ord expression is controlled post-transcriptionally

(A-B) Visualization of expression of ord over germline development from (A) bulk RNA-seq of developmentally enriched stages and (B) polysome-seq of developmentally enriched stages 
418 indicates that the mRNA level of ord is consistent from GSCs to cysts, until decreasing in early

419 egg chambers, but the translation efficiency of ord increases during the cyst stages compared to

420 other stages. Color indicates $(A)$ relative expression or $(B)$ TE and values indicate the $(A)$ mean

421 TPM \pm standard error or $(B)$ the $\log _{2}$ mean TE \pm standard error (C-C") Confocal images of ovaries

422 expressing Ord::GFP with in situ hybridization of gfp mRNA (red, middle greyscale) and stained

423 for GFP protein (green, right greyscale) and DAPI (blue) demonstrate that the mRNA level of

424 Ord::GFP is consistent throughout the germarium. (D-D') Quantification of normalized mean

425 intensity of stainings (C-C"). X-axis represents the distance in microns from the niche, Y-axis

426 represents mean intensity normalized to the maximum mean intensity per germarium of ord

427 mRNA (D) or Ord protein (D). The line represents fit using a loess regression, shaded area

428 represents the standard error of the fit. ( $n=8$ germaria). 
A

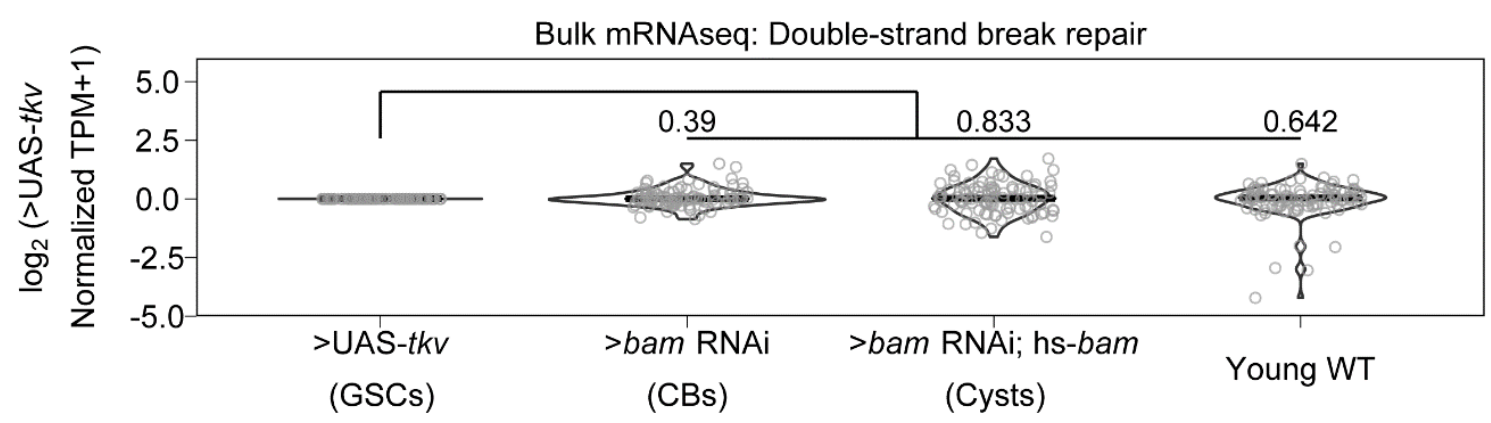

B

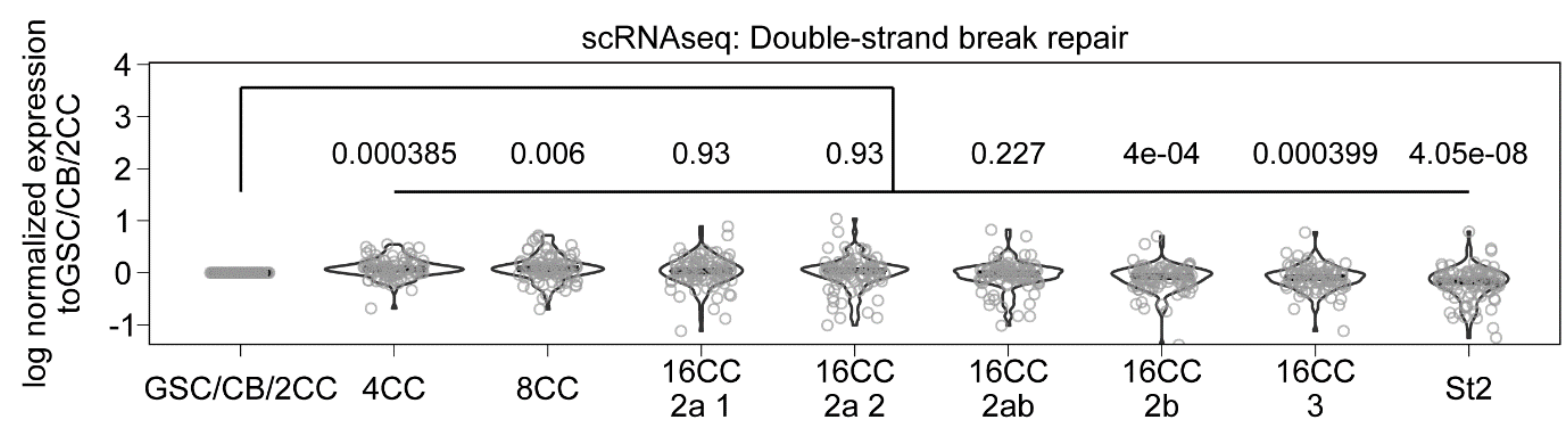

C

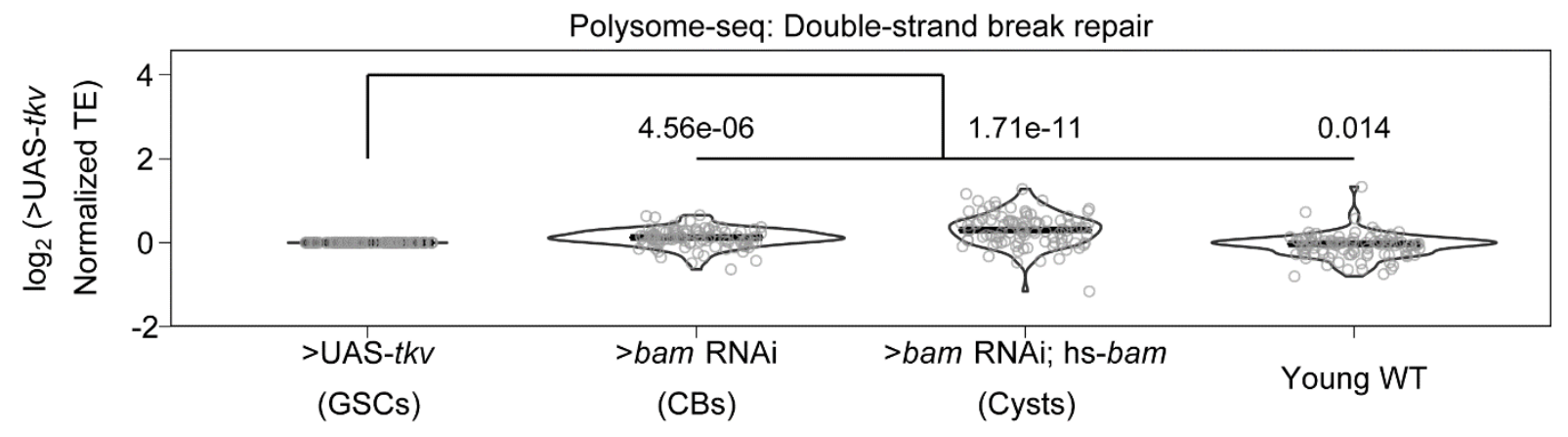

Figure 5. Genes involved in double-strand break repair may be controlled post432 transcriptionally.

433 (A) Violin plot of expression of genes in the GO category "Double-strand break repair" from bulk 434 RNA-seq. No significant overall change in expression of these genes occurs comparing each 435 genetically enriched developmental stage to GSCs. (B) Violin plot of expression of genes in the 436 GO category "Double-strand break repair" from scRNA-seq. Overall expression of these genes 437 increases in CBs, cysts, and young-WT ovaries compared to the GSC/CB/2CC cluster. Values 438 above plots represent Holm-Bonnferroni adjusted p-values from a Welch's t-test between the 
439 indicated genotypes (C) Violin plot of expression of genes in the GO category "Double-strand 440 break repair" from polysome-seq. Overall expression of these genes increases in CBs, cysts, and 441 young-WT ovaries compared to GSCs. Values above plots represent Holm-Bonnferroni adjusted 442 p-values from a Welch's t-test between the indicated genotypes. 
bioRxiv preprint doi: https://doi.org/10.1101/2022.01.31.478569; this version posted January 31, 2022. The copyright holder for this preprint (which was not certified by peer review) is the author/funder, who has granted bioRxiv a license to display the preprint in perpetuity. It is made available under aCC-BY-NC-ND 4.0 International license.

A

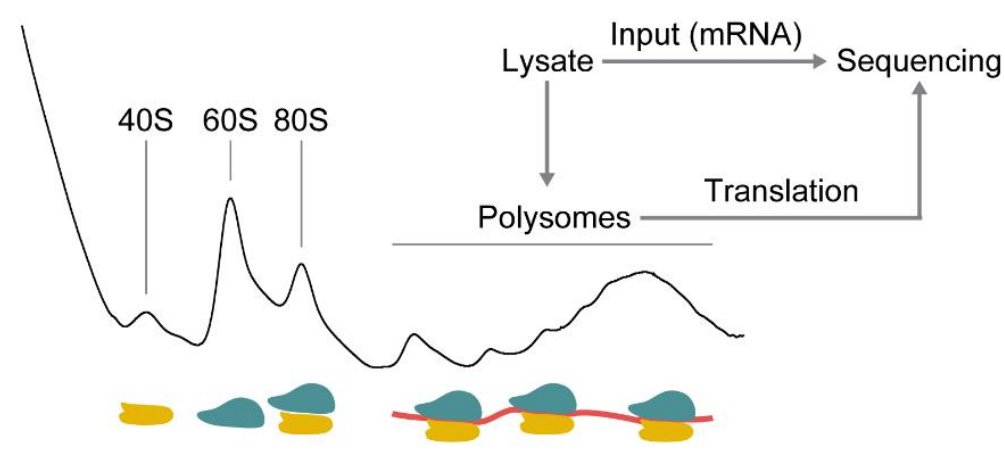

B

C

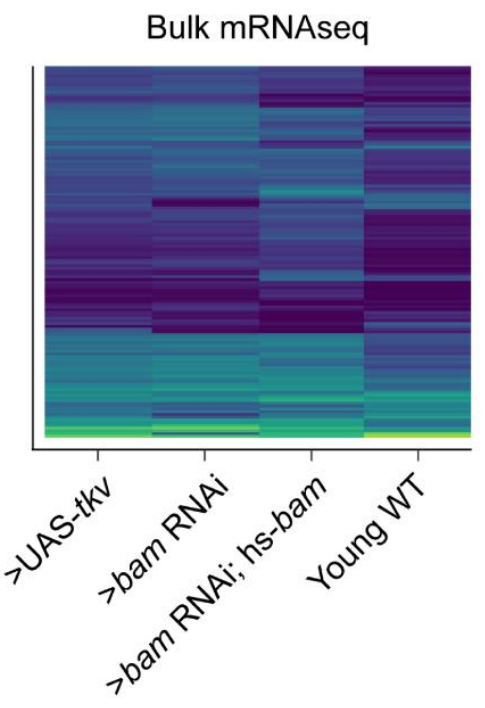

Germline SC-seq
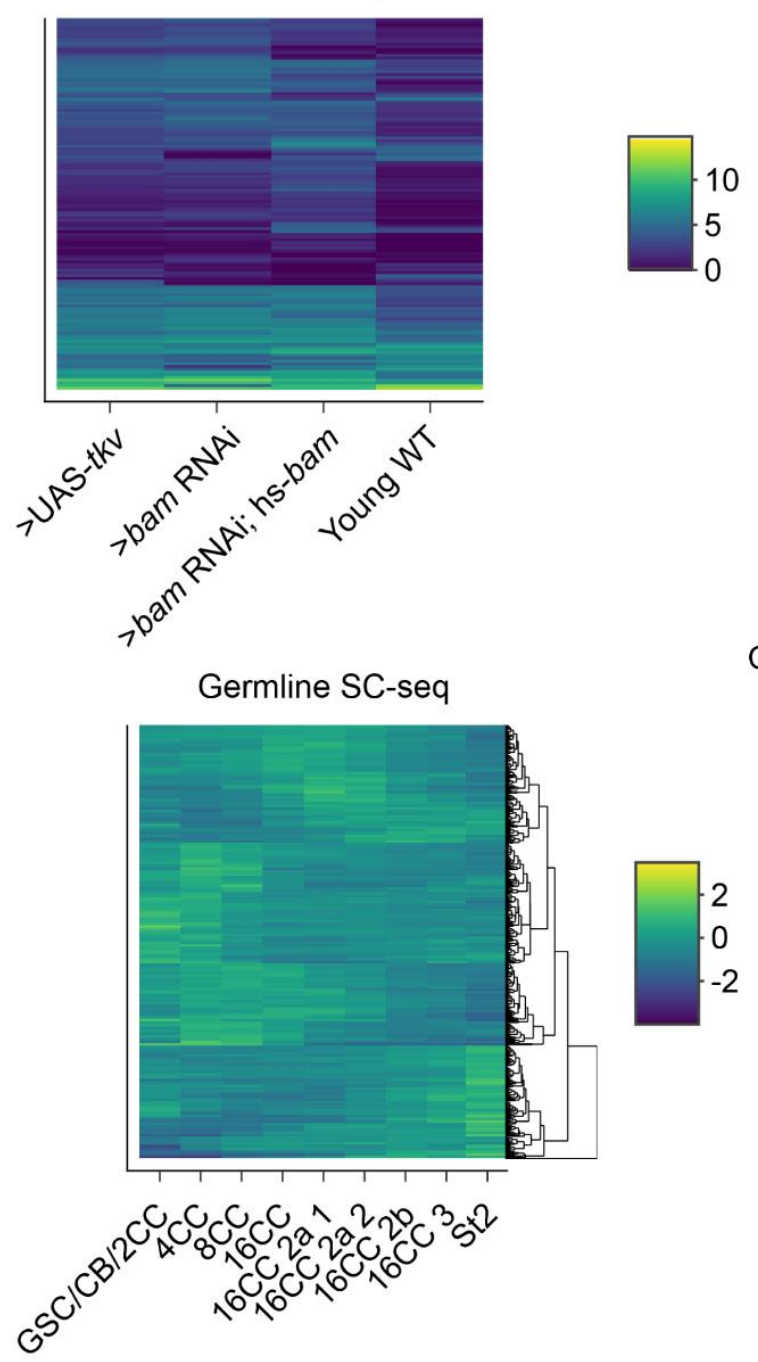

B'

$\mathrm{C}^{\prime}$
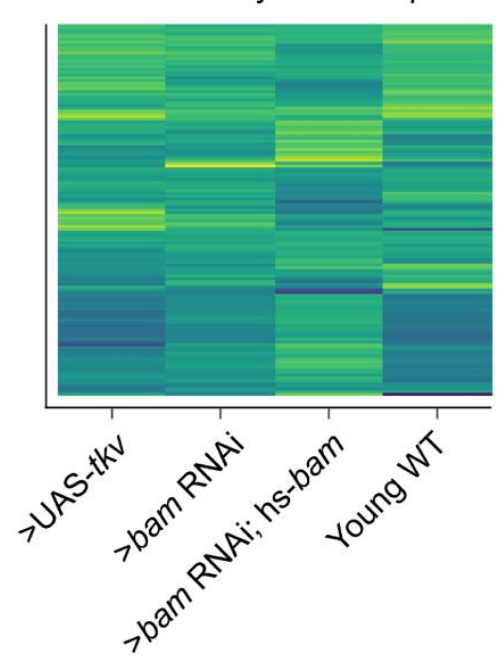

Soma SC-seq
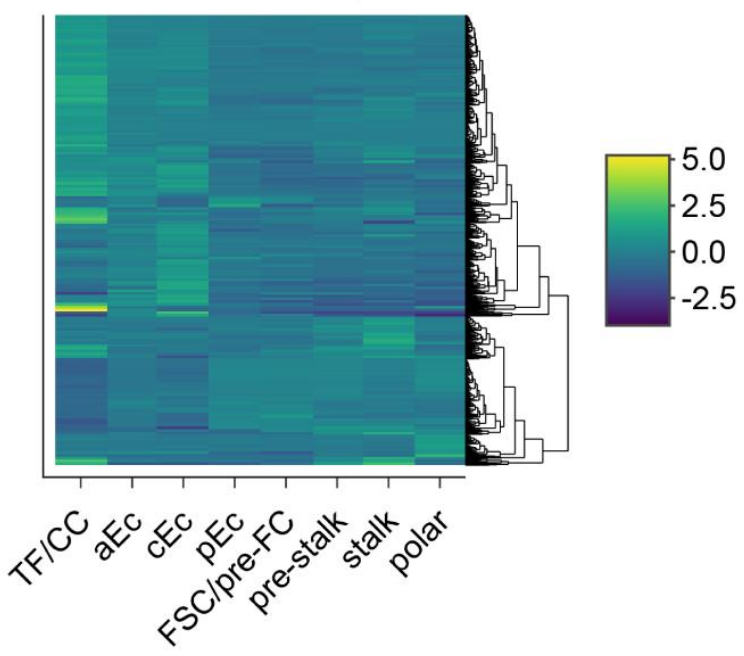
444 Supplemental Figure 1. Sequencing strategy and clustered heatmaps of differential 445 expression, related to Figure 1

446 (A) Schematic of strategy used to obtain input mRNA samples and matched polysome-seq

447 libraries of ovaries genetically enriched for developmental milestones. (B-B') Clustered heatmaps

448 of (B) bulk RNA-seq and (B') $\log _{2}(T E)$ from bulk polysome-seq of the developmental milestones

449 indicated on the X-axis. Each row in the heatmap indicates a gene that is differentially expressed

450 in at least one of the milestones compared to all others in a pairwise fashion. Color scale denotes

451 average relative expression. (C) scRNA-seq of early germline cells and (C') scRNA-seq of

452 somatic cells in the germarium. X-axis denotes cell-type and each row in the heatmap indicates

453 a gene that is differentially expressed in at least one of the cell-types compared to all others in a 454 pairwise fashion. 
A

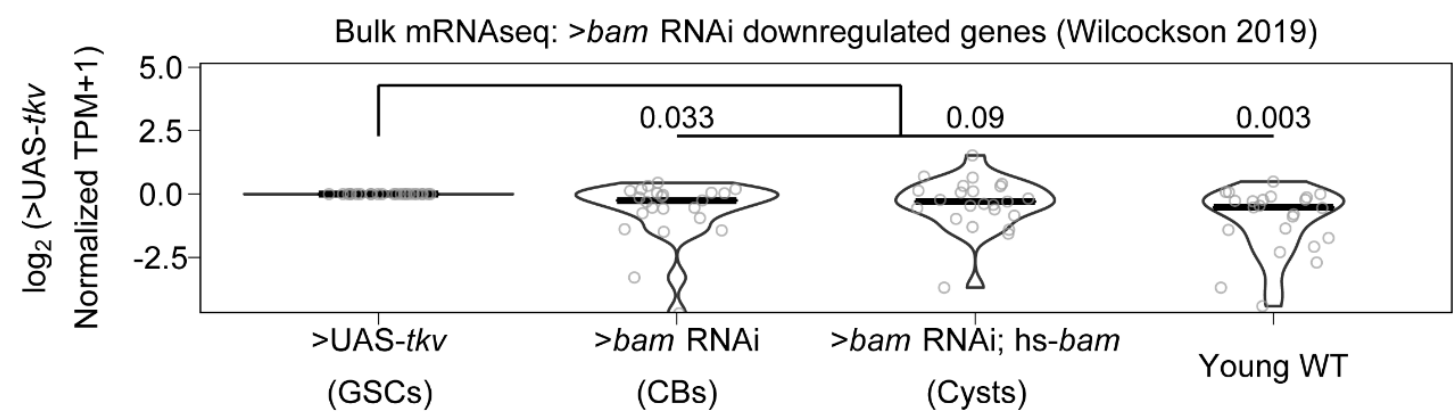

$A^{\prime}$

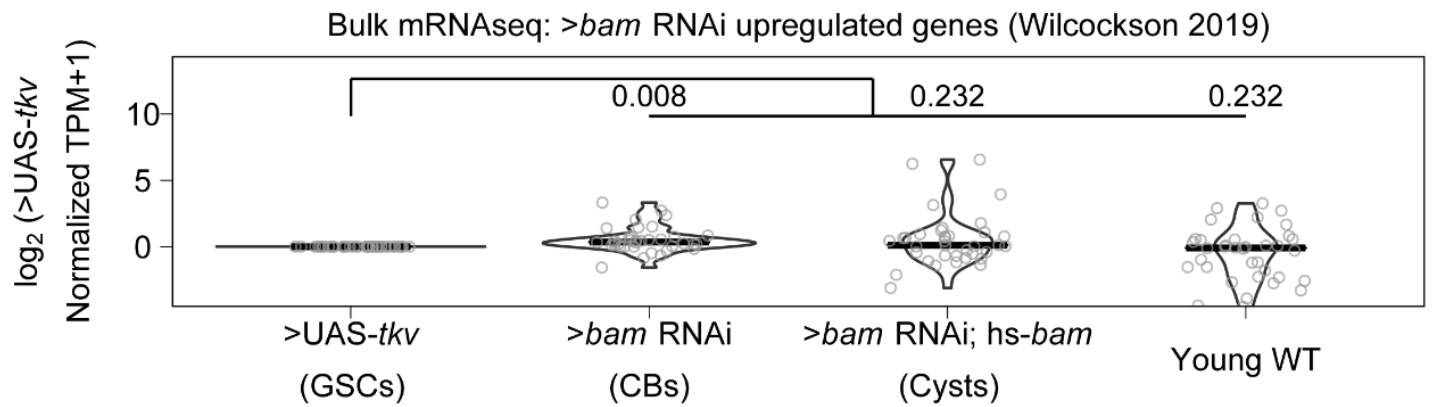

B

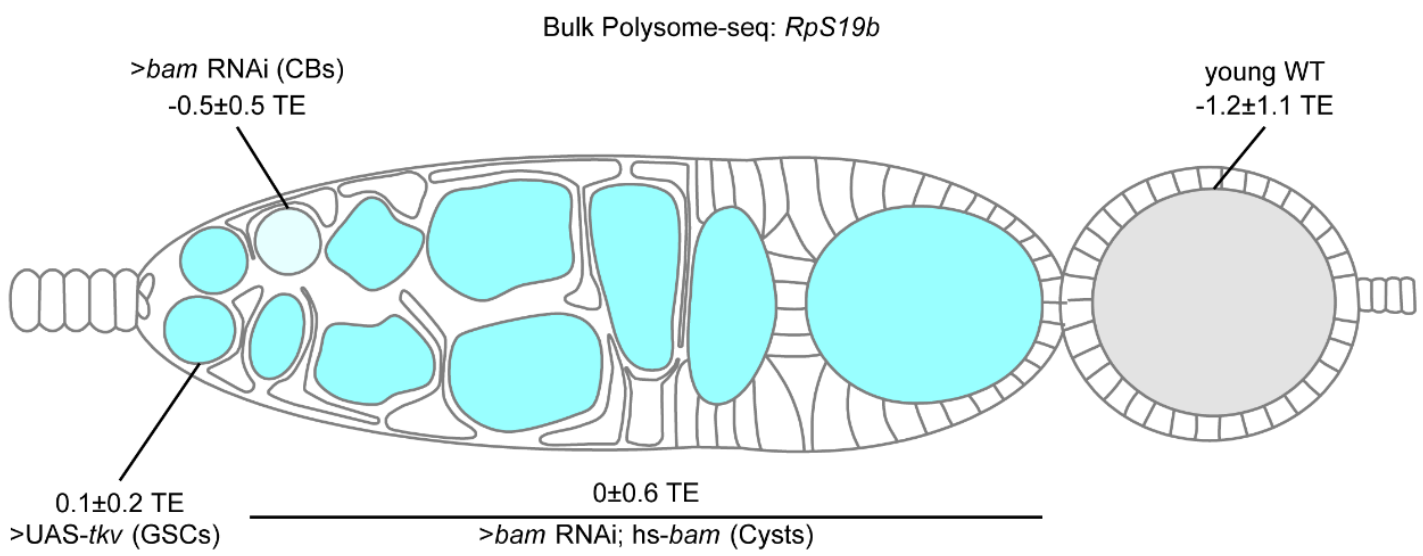

Supplemental Figure 2. Bulk RNA-seq recapitulates previously observed expression patterns of gene expression, related to Figure 2

459 (A-A') Violin plots of expression from bulk RNA-seq of genes 2-fold or more (A) down or ( $\left.A^{\prime}\right)$ 460 upregulated in bam RNAi germline cells compared to UAS-TKV overexpressing germline cell with 461 a p-value $<0.01$ over germline development from Wilcockson et al. demonstrate that bulk RNA462 seq identifies similar trends in gene expression compared to the FACS based method employed 463 by Wilcockson et al. Values above plots represent Holm-Bonnferroni adjusted p-values from a 464 Welch's t-test between the indicated genotypes. (B) Visualization of expression of RpS19b over 465 germline development from polysome-seq data. Color indicates TE and values indicate the $\log _{2}$ 
bioRxiv preprint doi: https://doi.org/10.1101/2022.01.31.478569; this version posted January 31, 2022. The copyright holder for this preprint (which was not certified by peer review) is the author/funder, who has granted bioRxiv a license to display the preprint in perpetuity. It is made available under aCC-BY-NC-ND 4.0 International license.

466 mean TE \pm standard error RpS19b TE is relatively consistent during early oogenesis and 467 decreases in the egg chambers.

468 
bioRxiv preprint doi: https://doi.org/10.1101/2022.01.31.478569; this version posted January 31, 2022. The copyright holder for this preprint (which was not certified by peer review) is the author/funder, who has granted bioRxiv a license to display the preprint in perpetuity. It is made available under aCC-BY-NC-ND 4.0 International license.

A

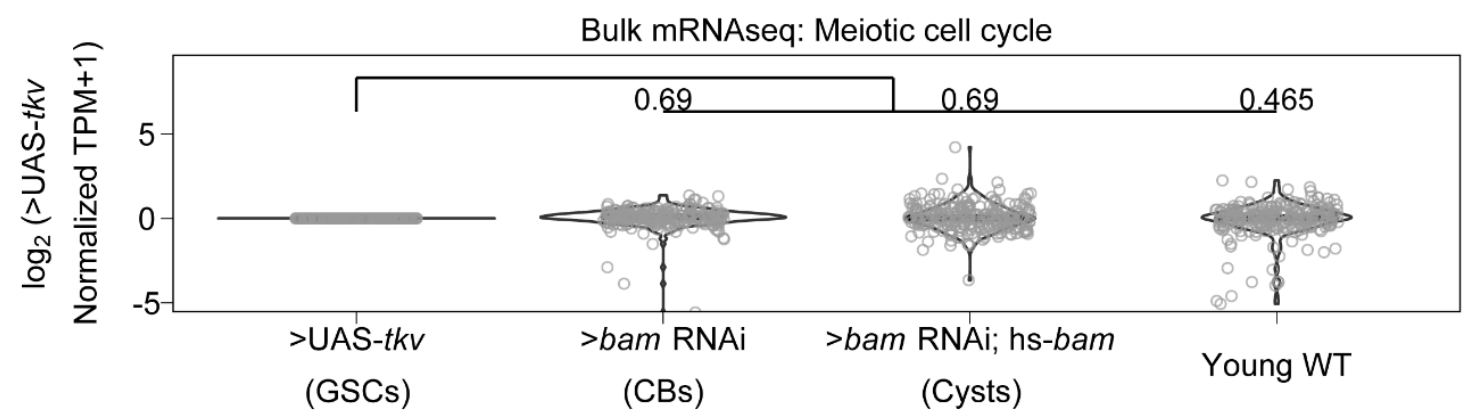

B

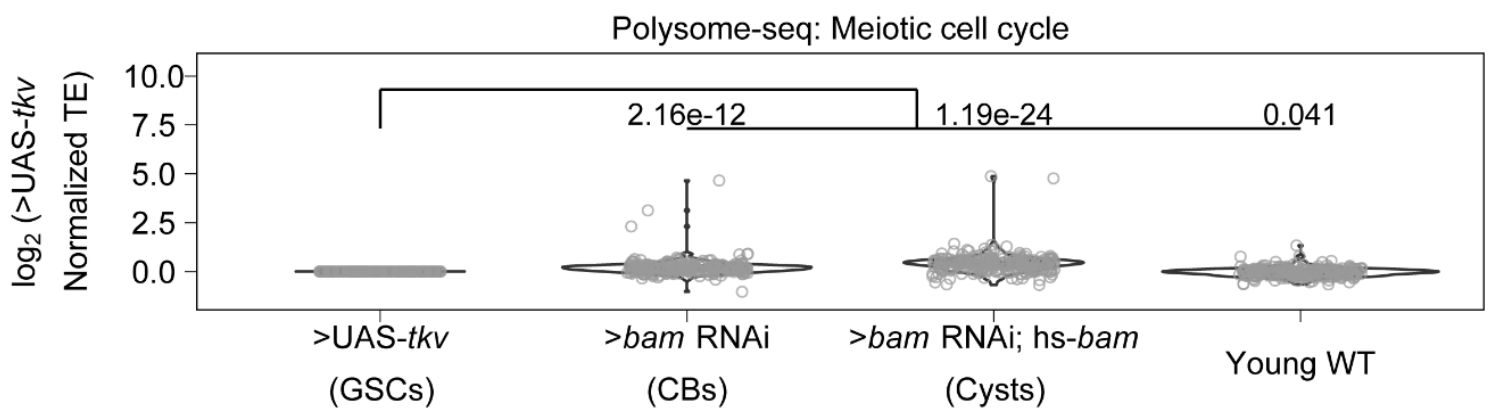

C

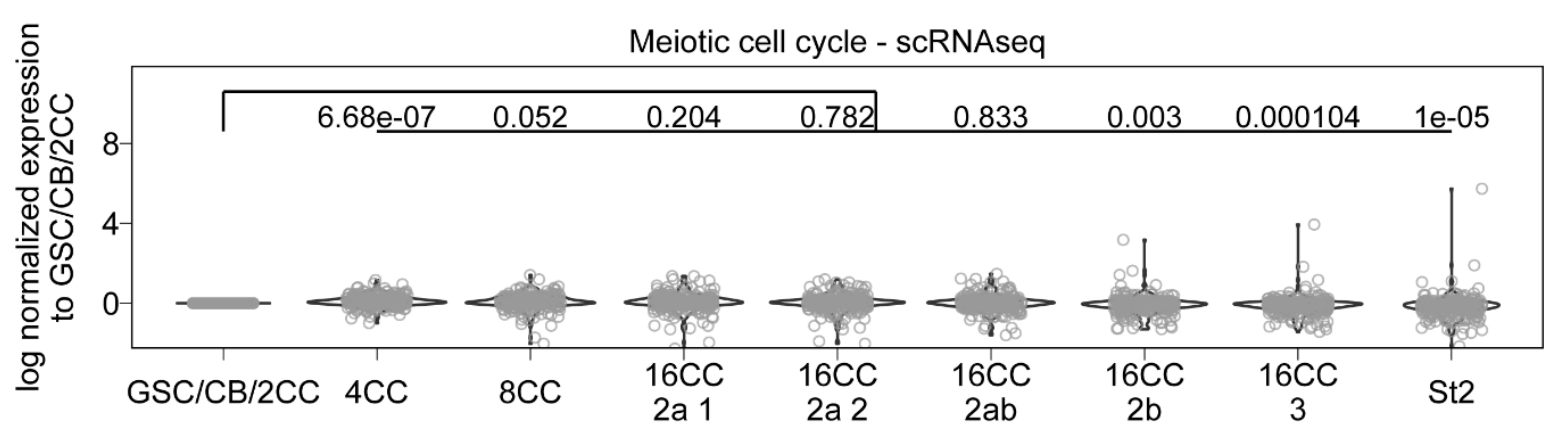

D

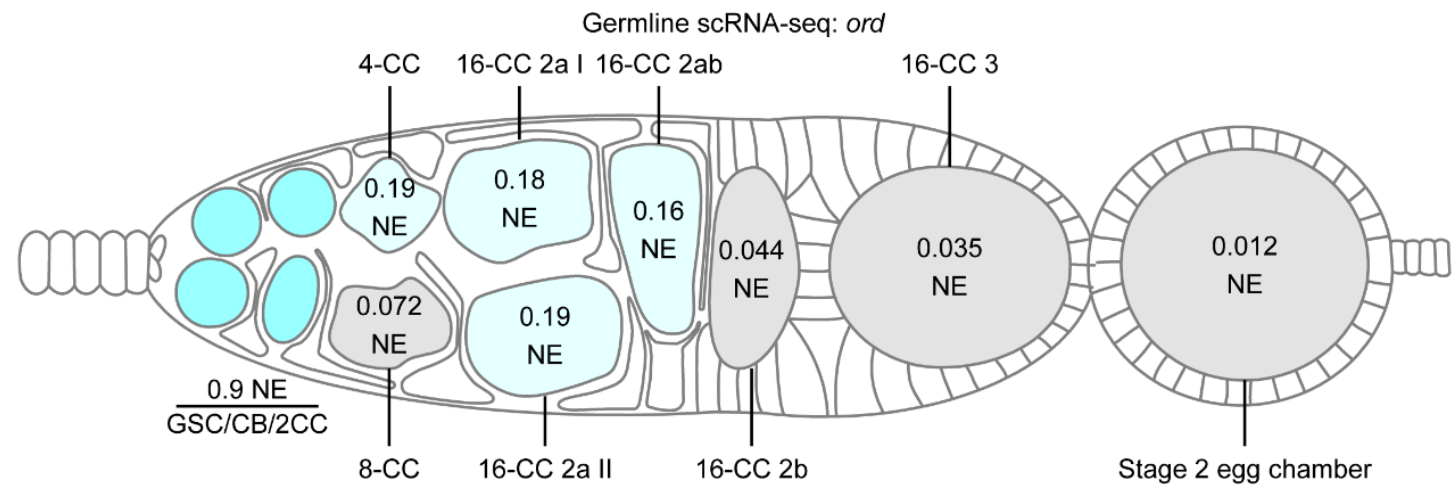

469

470 Supplemental Figure 3. Genes involved in meiotic cell cycle, including ord, may be 471 controlled post-transcriptionally, related to Figure 4.

472 (A) Violin plots of gene expression from RNA-seq of genes in the GO-term category meiotic cell 473 cycle. No significant overall change occurs to expression of these genes at any of the 
developmental milestones compared to GSCs. Values above plots represent Holm-Bonnferroni adjusted p-values from a Welch's t-test between the indicated genotypes. (B) Violin plots of TE from polysome-seq of genes in the GO-term category meiotic cell cycle. Overall TE increases in CBs and cysts significantly compared to GSCs indicating that meiotic entry may be partially controlled post-transcriptionally. Values above plots represent Holm-Bonnferroni adjusted pvalues from a Welch's t-test between the indicated genotypes. (C) Violin plot of expression of genes in the GO category "meiotic cell cycle" from scRNA-seq. Overall expression of these genes increases in CBs, cysts, and young-WT ovaries compared to the GSC/CB/2CC cluster. Values above plots represent Holm-Bonnferroni adjusted p-values from a Welch's t-test between the indicated genotypes. (D) scRNA-seq data indicate that the mRNA level of ord is highest in the $\mathrm{GSC} / \mathrm{CB} / 2 \mathrm{CC}$ cluster, but remains relatively consistent in its expression starting in the 4-CC through 16-CC 2ab clusters and is dramatically decreased in early egg chambers. Color and values indicate the normalized expression of ord in each given stage.

\section{References}

Bastock, R., St Johnston, D., 2008. Drosophila oogenesis. Curr. Biol. 18, R1082-R1087. of ORD, a Drosophila protein essential for sister chromatid cohesion. EMBO J. 15, 1451.

Bickel, S.E., Wyman, D.W., Orr-Weaver, T.L., 1997. Mutational Analysis of the Drosophila Sister-Chromatid Cohesion Protein ORD and Its Role in the Maintenance of Centromeric Cohesion. Genetics 146, 1319-1331. https://doi.org/10.1093/genetics/146.4.1319

Blatt, P., Martin, E.T., Breznak, S.M., Rangan, P., 2020. Post-transcriptional gene regulation regulates germline stem cell to oocyte transition during Drosophila oogenesis, in: Current Topics in Developmental Biology. Elsevier, pp. 3-34.

Cahoon, C.K., Hawley, R.S., 2016. Regulating the construction and demolition of the synaptonemal complex. Nat. Struct. Mol. Biol. 23, 369-377. https://doi.org/10.1038/nsmb.3208

Carpenter, A.T.C., 1979. Synaptonemal Complex and Recombination Nodules in Wild-Type Drosophila melanogaster Females. Genetics 92, 511.

Carpenter, A.T.C., 1975. Electron microscopy of meiosis in Drosophila melanogaster females. Chromosoma 51, 157-182. https://doi.org/10.1007/BF00319833

Carreira-Rosario, A., Bhargava, V., Hillebrand, J., Kollipara, R.K.K., Ramaswami, M., Buszczak, M., 2016. Repression of Pumilio Protein Expression by Rbfox1 Promotes Germ Cell Differentiation. Dev. Cell 36, 562-571. https://doi.org/10.1016/j.devcel.2016.02.010

Chen, D., McKearin, D., 2003a. Dpp Signaling Silences bam Transcription Directly to Establish Asymmetric Divisions of Germline Stem Cells. Curr. Biol. 13, 1786-1791. https://doi.org/10.1016/J.CUB.2003.09.033

Chen, D., McKearin, D.M., 2003b. A discrete transcriptional silencer in the bam gene determines asymmetric division of the Drosophila germline stem cell. Development 130, 1159-1170. https://doi.org/10.1242/dev.00325

Christophorou, N., Rubin, T., Huynh, J.-R., 2013. Synaptonemal Complex Components Promote Centromere Pairing in Pre-meiotic Germ Cells. PLOS Genet. 9, e1004012. https://doi.org/10.1371/journal.pgen.1004012 
De Cuevas, M., Spradling, A.C., 1998. Morphogenesis of the Drosophila fusome and its implications for oocyte specification. Development 125, 2781 LP - 2789.

Decotto, E., Spradling, A.C., 2005. The Drosophila ovarian and testis stem cell niches: similar somatic stem cells and signals. Dev. Cell 9, 501-510. https://doi.org/10.1016/j.devcel.2005.08.012

Eliazer, S., Buszczak, M., 2011. Finding a niche: studies from the Drosophila ovary. Stem Cell Res. Ther. 2, 45. https://doi.org/10.1186/scrt86

Flora, P., Wong-Deyrup, S.W., Martin, E.T., Palumbo, R.J., Nasrallah, M., Oligney, A., Blatt, P., Patel, D., Fuchs, G., Rangan, P., 2018. Sequential regulation of maternal mRNAs through a conserved cis-acting element in their 3' UTRs. Cell Rep. 25, 3828-3843.

Forbes, A.J., Lin, H., Ingham, P.W., Spradling, A.C., 1996. hedgehog is required for the proliferation and specification of ovarian somatic cells prior to egg chamber formation in Drosophila. Dev. Camb. Engl. 122, 1125-1135.

Han, R., Wang, X., Bachovchin, W., Zukowska, Z., Osborn, J.W., 2015. Inhibition of dipeptidyl peptidase 8/9 impairs preadipocyte differentiation. Sci. Rep. 5, 12348. https://doi.org/10.1038/srep12348

Hao, Y., Hao, S., Andersen-Nissen, E., Mauck, W.M., Zheng, S., Butler, A., Lee, M.J., Wilk, A.J., Darby, C., Zager, M., Hoffman, P., Stoeckius, M., Papalexi, E., Mimitou, E.P., Jain, J., Srivastava, A., Stuart, T., Fleming, L.M., Yeung, B., Rogers, A.J., McElrath, J.M., Blish, C.A., Gottardo, R., Smibert, P., Satija, R., 2021. Integrated analysis of multimodal single-cell data. Cell 184, 3573-3587.e29. https://doi.org/10.1016/j.cell.2021.04.048

Hinnant, T.D., Merkle, J.A., Ables, E.T., 2020. Coordinating Proliferation, Polarity, and Cell Fate in the Drosophila Female Germline. Front. Cell Dev. Biol. 0. https://doi.org/10.3389/fcell.2020.00019

Hughes, S.E., Miller, D.E., Miller, A.L., Hawley, R.S., 2018. Female Meiosis: Synapsis, Recombination, and Segregation in Drosophila melanogaster. Genetics 208, 875-908. https://doi.org/10.1534/genetics.117.300081

Huynh, J., St Johnston, D., 2000. The role of BicD, egl, orb and the microtubules in the restriction of meiosis to the Drosophila oocyte. Development 127, 2785-2794. https://doi.org/10.1242/dev.127.13.2785

Huynh, J.-R., St Johnston, D., 2004. The Origin of Asymmetry: Early Polarisation of the Drosophila Germline Cyst and Oocyte. Curr. Biol. 14, R438-R449. https://doi.org/10.1016/j.cub.2004.05.040

Joyce, E.F., Apostolopoulos, N., Beliveau, B.J., Wu, C. -ting, 2013. Germline Progenitors Escape the Widespread Phenomenon of Homolog Pairing during Drosophila Development. PLOS Genet. 9, e1004013. https://doi.org/10.1371/journal.pgen.1004013

Khetani, R.S., Bickel, S.E., 2007. Regulation of meiotic cohesion and chromosome core morphogenesis during pachytene in Drosophila oocytes. J. Cell Sci. 120, 3123-3137. https://doi.org/10.1242/jcs.009977

Kim-Ha, J., Kerr, K., Macdonald, P.M., 1995. Translational regulation of oskar mRNA by Bruno, an ovarian RNA-binding protein, is essential. Cell 81, 403-412. https://doi.org/10.1016/0092-8674(95)90393-3

Kirilly, D., Wang, S., Xie, T., 2011. Self-maintained escort cells form a germline stem cell differentiation niche. Development 138, 5087-5097. https://doi.org/10.1242/dev.067850

Lähnemann, D., Köster, J., Szczurek, E., McCarthy, D.J., Hicks, S.C., Robinson, M.D., Vallejos, C.A., Campbell, K.R., Beerenwinkel, N., Mahfouz, A., Pinello, L., Skums, P., Stamatakis, A., Attolini, C.S.-O., Aparicio, S., Baaijens, J., Balvert, M., Barbanson, B. de, Cappuccio, A., Corleone, G., Dutilh, B.E., Florescu, M., Guryev, V., Holmer, R., Jahn, K., Lobo, T.J., Keizer, E.M., Khatri, I., Kielbasa, S.M., Korbel, J.O., Kozlov, A.M., Kuo, T.-H., Lelieveldt, B.P.F., Mandoiu, I.I., Marioni, J.C., Marschall, T., Mölder, F., Niknejad, A., Raczkowski, L., Reinders, M., Ridder, J. de, Saliba, A.-E., Somarakis, A., Stegle, O., Theis, F.J., 
600

601

602

603

604

605

606

607

608

609

610

611

612

613

614

615

616

617

Yang, H., Zelikovsky, A., McHardy, A.C., Raphael, B.J., Shah, S.P., Schönhuth, A., 2020. Eleven grand challenges in single-cell data science. Genome Biol. 21, 31. https://doi.org/10.1186/s13059-020-1926-6

Lehmann, R., 2012. Germline Stem Cells: Origin and Destiny. Cell Stem Cell 10, 729-739. https://doi.org/10.1016/j.stem.2012.05.016

Li, Y., Minor, N.T., Park, J.K., McKearin, D.M., Maines, J.Z., 2009. Bam and Bgcn antagonize Nanos-dependent germ-line stem cell maintenance. Proc. Natl. Acad. Sci. 106, 9304 LP - 9309. https://doi.org/10.1073/pnas.0901452106

Lin, H., Spradling, A.C., 1993. Germline Stem Cell Division and Egg Chamber Development in Transplanted Drosophila Germaria. Dev. Biol. 159, 140-152. https://doi.org/10.1006/dbio.1993.1228

Love, M.I., Huber, W., Anders, S., 2014. Moderated estimation of fold change and dispersion for RNA-seq data with DESeq2. Genome Biol. 15, 550. https://doi.org/10.1186/s13059-0140550-8

Margolis, J., Spradling, A., 1995. Identification and behavior of epithelial stem cells in the Drosophila ovary. Development 121, 3797 LP - 3807.

McCarthy, A., Sarkar, K., Martin, E.T., Upadhyay, M., Jang, S., Williams, N.D., Forni, P.E., Buszczak, M., Rangan, P., 2021. MSL3 promotes germline stem cell differentiation in female Drosophila. Development dev.199625. https://doi.org/10.1242/dev.199625

McKearin, D., Ohlstein, B., 1995. A role for the Drosophila bag-of-marbles protein in the differentiation of cystoblasts from germline stem cells. Development 121, 2937 LP 2947.

Mehrotra, S., McKim, K.S., 2006. Temporal Analysis of Meiotic DNA Double-Strand Break Formation and Repair in Drosophila Females. PLOS Genet. 2, e200. https://doi.org/10.1371/journal.pgen.0020200

Navarro, C., Lehmann, R., Morris, J., 2001. Oogenesis: Setting one sister above the rest. Curr. Biol. 11, R162-R165. https://doi.org/10.1016/S0960-9822(01)00083-5

Nystul, T., Spradling, A., 2010. Regulation of Epithelial Stem Cell Replacement and Follicle Formation in the Drosophila Ovary. Genetics 184, 503-515. https://doi.org/10.1534/genetics.109.109538

Ohlstein, B., McKearin, D., 1997. Ectopic expression of the Drosophila Bam protein eliminates oogenic germline stem cells. Development 124, 3651-3662.

Page, S.L., Hawley, R.S., 2003. Chromosome Choreography: The Meiotic Ballet. Science. https://doi.org/10.1126/science.1086605

Perišić Nanut, M., Pečar Fonović, U., Jakoš, T., Kos, J., 2021. The Role of Cysteine Peptidases in Hematopoietic Stem Cell Differentiation and Modulation of Immune System Function. Front. Immunol. 12.

Roth, S., 2001. Drosophila oogenesis: Coordinating germ line and soma. Curr. Biol. 11, R779R781. https://doi.org/10.1016/S0960-9822(01)00469-9

Rubin, T., Macaisne, N., Huynh, J.-R., 2020. Mixing and Matching Chromosomes during Female Meiosis. Cells 9, 696. https://doi.org/10.3390/cells9030696

Rust, K., Byrnes, L.E., Yu, K.S., Park, J.S., Sneddon, J.B., Tward, A.D., Nystul, T.G., 2020. A single-cell atlas and lineage analysis of the adult Drosophila ovary. Nat. Commun. 11, 5628. https://doi.org/10.1038/s41467-020-19361-0

Sahai-Hernandez, P., Castanieto, A., Nystul, T.G., 2012. Drosophila models of epithelial stem cells and their niches. WIREs Dev. Biol. 1, 447-457. https://doi.org/10.1002/wdev.36

Sarkar, K., Kotb, N.M., Lemus, A., Martin, E.T., McCarthy, A., Camacho, J., lqbal, A., Valm, A.M., Sammons, M.A., Rangan, P., 2021. A feedback loop between heterochromatin and the nucleopore complex controls germ-cell to oocyte transition during Drosophila oogenesis. https://doi.org/10.1101/2021.10.31.466575 
652

653

654

655

656

657

658

659

660

661

662

663

664

665

666

667

Schüpbach, T., 1987. Germ line and soma cooperate during oogenesis to establish the dorsoventral pattern of egg shell and embryo in Drosophila melanogaster. Cell 49, 699707. https://doi.org/10.1016/0092-8674(87)90546-0

Shachak, A., Shuval, K., Fine, S., 2007. Barriers and enablers to the acceptance of bioinformatics tools: a qualitative study. J. Med. Libr. Assoc. JMLA 95, 454. https://doi.org/10.3163/1536-5050.95.4.454

Shi, J., Jin, Z., Yu, Y., Zhang, Y., Yang, F., Huang, H., Cai, T., Xi, R., 2021. A Progressive Somatic Cell Niche Regulates Germline Cyst Differentiation in the Drosophila Ovary. Curr. Biol. 31, 840-852.e5. https://doi.org/10.1016/j.cub.2020.11.053

Slaidina, M., Gupta, S., Banisch, T.U., Lehmann, R., 2021. A single-cell atlas reveals unanticipated cell type complexity in Drosophila ovaries. Genome Res. gr.274340.120. https://doi.org/10.1101/gr.274340.120

Slaidina, M., Lehmann, R., 2014. Translational control in germline stem cell development. J. Cell Biol. 207, 13 LP - 21. https://doi.org/10.1083/jcb.201407102

Spradling, A., Fuller, M.T., Braun, R.E., Yoshida, S., 2011. Germline stem cells. Cold Spring Harb. Perspect. Biol. 3, a002642. https://doi.org/10.1101/cshperspect.a002642

Tanneti, N.S., Landy, K., Joyce, E.F., McKim, K.S., 2011. A Pathway for Synapsis Initiation during Zygotene in Drosophila Oocytes. Curr. Biol. 21, 1852-1857. https://doi.org/10.1016/j.cub.2011.10.005

Tastan, Ö.Y., Maines, J.Z., Li, Y., Mckearin, D.M., Buszczak, M., 2010. Drosophila Ataxin 2binding protein 1 marks an intermediate step in the molecular differentiation of female germline cysts. Development 137, 3167-3176. https://doi.org/10.1242/dev.050575

Theurkauf, W.E., Alberts, B.M., Jan, Y.N., Jongens, T.A., 1993. A central role for microtubules in the differentiation of Drosophila oocytes. Dev. Camb. Engl. 118, 1169-80.

Tiaden, A.N., Breiden, M., Mirsaidi, A., Weber, F.A., Bahrenberg, G., Glanz, S., Cinelli, P., Ehrmann, M., Richards, P.J., 2012. Human serine protease HTRA1 positively regulates osteogenesis of human bone marrow-derived mesenchymal stem cells and mineralization of differentiating bone-forming cells through the modulation of extracellular matrix protein. Stem Cells Dayt. Ohio 30, 2271-2282. https://doi.org/10.1002/stem.1190

Upadhyay, M., Cortez, Y.M., Wong-Deyrup, S., Tavares, L., Schowalter, S., Flora, P., Hill, C., Nasrallah, M.A., Chittur, S., Rangan, P., 2016. Transposon Dysregulation Modulates dWnt4 Signaling to Control Germline Stem Cell Differentiation in Drosophila. PLOS Genet. 12, e1005918. https://doi.org/10.1371/journal.pgen.1005918

Wang, X., Page-McCaw, A., 2018. Wnt6 maintains anterior escort cells as an integral component of the germline stem cell niche. Dev. Camb. Engl. 145. https://doi.org/10.1242/dev.158527

Wei, Y., Reveal, B., Reich, J., Laursen, W.J., Senger, S., Akbar, T., lida-Jones, T., Cai, W., Jarnik, M., Lilly, M.A., 2014. TORC1 regulators Iml1/GATOR1 and GATOR2 control meiotic entry and oocyte development in Drosophila. Proc. Natl. Acad. Sci. 111, E5670E5677.

Wickham, H., 2016. ggplot2: Elegant graphics for data analysis. Springer-Verlag New York.

Wilcockson, S.G., Ashe, H.L., 2019. Drosophila Ovarian Germline Stem Cell Cytocensor Projections Dynamically Receive and Attenuate BMP Signaling. Dev. Cell 50, 296312.e5. https://doi.org/10.1016/j.devcel.2019.05.020

Xie, T., Spradling, A.C., 2000. A Niche Maintaining Germ Line Stem Cells in the Drosophila Ovary. Science 290, 328-330. https://doi.org/10.1126/science.290.5490.328

Xie, T., Spradling, A.C., 1998. decapentaplegic Is Essential for the Maintenance and Division of Germline Stem Cells in the Drosophila Ovary. Cell 94, 251-260. https://doi.org/10.1016/S0092-8674(00)81424-5 
bioRxiv preprint doi: https://doi.org/10.1101/2022.01.31.478569; this version posted January 31, 2022. The copyright holder for this preprint (which was not certified by peer review) is the author/funder, who has granted bioRxiv a license to display the preprint in perpetuity. It is made available under aCC-BY-NC-ND 4.0 International license.

668

669

670
Zaccai, M., Lipshitz, H.D., 1996. Differential distributions of two adducin-like protein isoforms in the Drosophila ovary and early embryo. Zygote 4, 159-166. 